\title{
Impulsos climáticos da evolução na Amazônia durante o Cenozóico: sobre a teoria dos Refúgios da diferenciação biótica
}

\author{
J. HAFFER e G. T. PRANCE
}

\section{Introdução}

$\mathrm{E}$ XTEnsos Dados dos trópicos do Velho Mundo atestam a ocorrência de numerosos períodos secos nessas regiões durante os últimos 60 milhões de anos (Terciário e Quaternário). África e Austrália experimentaram uma sucessão de ciclos climáticos úmidos/secos e, durante os últimos 2,8 milhões de anos, foram submetidas a periódicas fases frias/secas correspondentes à sucessão de estágios glaciais do Plio-Pleistoceno. Na África tropical os níveis dos lagos foram intensamente reduzidos durante essas fases climáticas. Todavia, é provável que as mudanças não ocorreram homogeneamente nos continentes. Numa revisão global da origem e evolução das florestas pluviais tropicais Morley (2000: XIII, 280) enfatizou que "sua imensa diversidade é devida não a uma história longa e imutável, com condições climáticas estáveis ao longo de milhares de anos, mas à capacidade de plantas oportunísticas sobreviverem em períodos de mudança climática e perturbações geológicas, para expandir suas distribuições quando as mudanças climáticas permitiram, ou abrigar-se em refúgios favoráveis quando os climas eram desfavoráveis. A diversificação das floras de florestas pluviais tropicais continuou durante a maior parte do Terciário, como resultado de sua sucessiva expansão, retração e fragmentação por barreiras físicas, e não é um fenômeno exclusivo do Quaternário". A recorrência de eventos de clima seco, e seus efeitos associados às floras e faunas do Velho Mundo durante o Cenozóico (Terciário e Quaternário), têm sido amplamente considerados como o principal agente impulsor que antecede as respostas evolucionárias da biota (veja vários capítulos em Goldblatt, 1993 e Vrba et al., 1995). Qual era a situação na América do Sul, particularmente na Amazônia, durante esses períodos geológicos? Sua história climática teria seguido o padrão global? O objetivo deste trabalho é resumir e examinar o estágio atual de nosso conhecimento acerca da história climático-vegetacional da Amazônia e sua relevância para a evolução das floras e faunas florestais do Neotrópico.

É provável que a maioria das espécies de plantas e animais tenha surgido a partir de populações que desenvolveram mecanismos de isolamento genético- 
reprodutivo das espécies que as originaram durante um ou mais períodos de separação geográfica (especiação geográfica ou alopátrica; Mayr, 1942, 1963; Avise, 2000). A especiação simpátrica dentro do centro de origem de espécies parentais sem separação geográfica foi muito rara (Tregenza \& Butlin, 1999). Por conseguinte, surge a questão de como os diferentes tipos de barreira teriam fragmentado repetidamente os centros de origem de espécies ancestrais na Amazônia para permitir o desenvolvimento de novas espécies. Com as perturbações penetrantes intermediárias das florestas, causadas por erosão e migração lateral de rios nas planícies de inundação e por formações de lacunas (tormentas e derrubada de árvores), desenvolveu-se um mosaico complexo de floresta maturada, sucessões e lacunas que ajudam a explicar a manutenção da elevada diversidade de espécies na Amazônia. Entretanto, essas perturbações proporcionam insuficiente separação entre populações de plantas e animais para que se diferenciem em novas subespécies e espécies.

\section{O efeito dos períodos climáticos secos na Amazônia durante o Quaternário}

A resolução do registro geológico pertencente ao Terciário e a períodos universais mais antigos não foi suficientemente pormenorizada para documentar o efeito global dos ciclos astronômicos de Milankovitch, " exceto em determinadas situações locais (Herbert \& Fisher, 1986; Bartlein \& Prentice, 1989; Bennett, 1997). Esses ciclos nos períodos de ocorrência compreendidos entre 20 mil e 100 mil anos são: 1 ciclos de precessão (cerca de 20 mil anos) em virtude da variação na distância entre a Terra e o Sol; 2 ciclos de obliqüidade (cerca de 40 mil anos) em razão do acréscimo e decréscimo da inclinação do Equador na órbita da Terra ao redor do Sol; e 3 ciclos de excentricidade (cerca de 100 mil anos) por causa da variação na forma da órbita da Terra ao redor do Sol. Seu principal efeito foi uma alteração dos períodos climáticos relativamente secos ou mais úmidos nos continentes, com mudanças correspondentes na distribuição da vegetação florestal e não-florestal. Tais oscilações de períodos geologicamente curtos (alta freqüência) foram sobrepostas a uma tendência de resfriamento gradual do clima da Terra desde o início do Cenozóico. O gradiente térmico latitudinal tornou-se alcantilado durante o curso do Terciário, quando a média anual de temperatura aumentou nos trópicos e as temperaturas de verão diminuíram nas latitudes mais elevadas. Durante o Quaternário os períodos relativamente secos (glaciais) foram mais frios também nos trópicos e os períodos interglaciais úmidos foram relativamente quentes.

O efeito biótico de tais mudanças climáticas durante o Quaternário e o Terciário foi que as comunidades romperam-se e as espécies mudaram suas dis-

\footnotetext{
* Milutin Milankovitch (1879-1958) foi professor de Física Teórica e Mecânica Celeste na Universidade de Belgrado e analisou, durante o início da década de 1930, os três padrões de flutuações climáticas globais durante a maior parte ou a totalidade da história geológica da Terra.
} 
tribuições de maneira individual. Não obstante, havia sempre tipos de vegetação fechada (florestas) e tipos abertos, com suas respectivas comunidades animais, durante as várias fases climáticas, ainda que suas composições específicas variassem em certo grau. Em razão dessas alterações nas comunidades, não falaremos de mudanças das "formações" de plantas.

Embora boa soma de dados ainda esteja esparsa, nos últimos anos ficou disponível muita informação sobre o efeito de climas secos (não necessariamente climas "áridos") na Amazônia durante o Quaternário Tardio (fig. 1). Entretanto, a exata datação e a correlação dos registros geológicos em diferentes domínios permanecem abertos em muitos casos. O importante a estabelecer neste estágio é o fato geral de que as fases climáticas secas e a correspondente redução de florestas pluviais úmidas ocorreram em algumas partes da Amazônia. Com este propósito, mesmo um indício não-datado de seca no passado é um "dado" que não deve ser desprezado. Não consideramos os resultados mencionados a seguir como prova da ocorrência de fases climáticas secas por toda a Amazônia durante o Quaternário, mas eles indicam alterações climáticas pelo menos em áreas localizadas e razoavelmente regionais. É claro que extensas áreas de floresta pluvial (que é muito antiga) sempre existiram na Amazônia. Burnham \& Graham (1999) e Thomas (2000) analisaram a evidência para seca climática na Amazônia em suas excelentes revisões das alterações ambientais do Quaternário em meios tropicais úmidos da Região Neotropical e do mundo, respectivamente.

Grandes campos inativos de dunas foram descobertos na região norte-central da Amazônia; essa área, o "Pantanal do Norte", cobre uma superfície de alguns milhares de quilômetros quadrados entre os rios Branco e Negro (Santos et al., 1993; veja fig. 1, n. 1) e hoje está coberta especialmente por vegetação aberta que é chamada localmente de caatinga amazônica. Contudo, a importância paleoclimática desses campos de areia pode ser limitada se, pelo reexame, ficar demonstrado tratar-se de areias podzólicas (de ampla distribuição no sistema do Rio Negro). Numerosos campos de areia eólicos menores existem mais ao norte, ao redor de Boa Vista (Carneiro Filho \& Zinck, 1994), e, na Amazônia Central, entre Manaus e o Oceano Atlântico. Sua vegetação, semelhante à caatinga, é chamada campina (Anderson, 1981), que também cobre pequenas áreas de leitos de rio emergentes próximos a Manaus (é claro que estas têm pouco a ver com climas relativamente secos). Essa vegetação é bem diferente daquela das savanas. São as savanas isoladas sobre os solos argilosos que mostram que suas plantas foram distribuídas amplamente na Amazônia; por exemplo, as savanas ao redor de Santarém e a Savana da Amélia, na ribanceira sul do Rio Negro, acima de Manaus. Iriondo \& Latrubesse (1994) ofereceram indícios para um clima seco da Época Glacial Tardia, na porção central da Amazônia inferior, e fizeram comentários sobre as descargas reduzidas dos rios nessa área e sob condições climáticas altamente sazonais com alísios acentuados. Os últimos autores afirmaram que somente mudanças de segunda ordem na dinâmica climática regional são sufi- 
cientes para documentar a ocorrência de uma fase climática seca nessa região (fig. 1, n. 2). Nessa mesma área, a oeste de Santarém (próximo a Óbidos), Tricart (1974: 146) observou "uma área altamente dissecada, apesar da cobertura de densa floresta (...) os declives são muito íngremes e os divisores muito estreitos. Tal dissecação não poderia desenvolver-se sob uma cobertura florestal densa. Ela envolve vegetação esparsa, mais ou menos do tipo de savana". Depois concluiu: "A Amazônia Central sofreu os efeitos de períodos secos quando deixou de ser recoberta pelo tipo atual de floresta pluvial (...) Dissecação densa e pronunciada dos divisores (...) desenvolvida durante o último período do nível baixo do mar, isto é, o último estágio da glaciação Würmiana (Wisconsin). Durante esse período é bem provável que a Amazônia Central não fosse coberta pela atual floresta pluvial fito-estabilizante, mas por tipos de vegetação mais seca sob os quais o escoamento foi capaz de produzir a dissecação dos declives" (Tricart, 1985: 197, 201). Condições úmidas e florestas de galeria provavelmente persistiram ao longo de porções do próprio Rio Amazonas e de seus principais tributários, como acontece hoje nas regiões de savanas da América do Sul; assim, isso não pode ser considerado como evidência contra um clima regionalmente seco (Müller et al., 1995). A importância desses corredores florestais foi enfatizada por Prance (1982 a).

A floresta pluvial em Pitinga, a cerca de 250 quilômetros ao norte de Manaus, está assentada em camadas de sedimentos grossos diversos, extremamente pobres, que devem ter sido depositados sob condições climáticas secas, de passado geológico recente, quando florestas pluviais densas de há muito estavam ausentes dessa região (Veiga et al., 1988; fig. 1, n. 3). A mesma interpretação aplica-se aos sedimentos depositados em partes do sul-central da Amazônia brasileira, nas regiões dos rios Xingu superior e médio Tapajós e do norte de Rondônia (Veiga et al., 1988, 1991; Bettencourt et al., 1988). Detritos grossos acumularam-se nas depressões superficiais na região média do Rio Tapajós (fig. 1, n. 4) e extensas camadas de areia cobriram as terras baixas ao redor da Serra do Cachimbo (fig. 1, n. 5) durante um período de forte erosão, quando o clima do Pleistoceno Tardio era seco e a vegetação da densa floresta pluvial havia em grande parte desaparecido dessas regiões (Bibus, 1983). Em vários perfis complexos de solo, o último autor observou camadas discrepantes indicativas de mudanças climáticas, acompanhadas por forte atividade morfodinâmica. Na Amazônia Meridional, aparecem colinas constituídas de granito parcialmente alterado (!) sob floresta pluvial, cuja situação só pode ser explicada por períodos intermediários de erosão, quando a cobertura florestal era mais aberta ou havia desaparecido completamente. Na região do Rio Tapajós ocorreu uma extensa fase de erosão durante o Pleistoceno Tardio, quando vegetação aberta cobria essa parte da Amazônia. Bibus (l.c.) também chamou a atenção para o fato de que os terraços do Pleistoceno na Amazônia Inferior contêm espessas camadas de sedimentos grossos, indicando condições de erosão muito diferentes no Baixo Amazonas, durante os períodos de deposição fluvial existentes atualmente nessa região. Observações geomorfo- 
lógicas em linhas de seixos e solos estratificados em Rondônia (Emmerich, 1988), ao redor de Porto Velho e estudos fitogeográficos próximos a Humaitá (Gottsberger \& Morawetz, 1986) também indicam climas secos e existência periódica de vegetação aberta nessa parte do sul da Amazônia durante o Plio-Pleistoceno (fig. 1, n. 6-7). Entre 9 mil e 3 mil anos BP (Before Present) a vegetação de savanas expandiu-se à custa de florestas na área de Humaitá e Porto Velho (Freitas et al., 2001). Estudo palinológico de Van der Hammen \& Absy (1994) indicou também a existência de vegetação de savana nessa região florestal, ao sudeste de Porto Velho, durante o Último Máximo Glacial. Mayle et al. (2000) documentaram mudanças na vegetação perto do limite sul da região da floresta amazônica.

Ao longo da sub-bacia do Acre, no oeste brasileiro (Rio Purus superior e Rio Acre inferior), precipitados de gesso e aragonita, associados com sedimentos de fina granulação, indicam o dessecamento de um extenso sistema fluvial-lacustre em virtude de condições climáticas secas há cerca de 53 mil anos (Kronberg et al., 1991; veja fig. 1, n. 8). ${ }^{*}$ Ademais, estudos paleontológicos de mamíferos fósseis das últimas regiões (e ao longo do Rio Napo no leste do Equador) indicam que uma vegetação constituída de savanas arborizadas e florestas de galeria se distribuía amplamente na Amazônia Ocidental durante o Pleistoceno Tardio, antes que as densas florestas pluviais cobrissem novamente essa região (Rancy, 1991; Webb \& Rancy, 1996; veja fig. 1, n. 9). Restos da fauna do Pleistoceno Tardio em sedimentos das planícies de inundação do Rio Juruá, no oés-sudoeste da Amazônia, também indicam campinas antes de 40 mil BP (Latrubesse \& Rancy 1998). Marshall (1979), Webb (1991) e Webb \& Rancy (1996) analisaram evidências de períodos climáticos secos nas terras baixas da América Central e do Sul, há vários milhões de anos, que permitiram uma troca da fauna dos mamíferos do norte e do sul pelos corredores de vegetação aberta da Amazônia.

Dados sobre pólen fóssil da região média do Rio Caquetá, no sudeste da Colômbia, indicaram que, durante períodos mais secos do Pleniglacial, tipos de vegetação savana-caatinga poderiam ter-se desenvolvido lá ou se expandido um pouco pelos arredores (fig. 1, n. 10). Os tabuleiros relativamente pequenos da Serra dos Carajás, no Estado do Pará, estão hoje cobertos com vegetação em solo de canga ferrífera, em razão das condições edáficas, e são circundados, em todos os lados da Serra, por extensas florestas pluviais biodiversas que cobrem os declives e os grotões intercalados (veja Secco \& Mesquita, 1983 e fig. 1, n. 11). Estudos geológicos e análises de pólen fóssil revelaram quatro períodos de regressão de floresta pluvial dessa região geral, durante os últimos 60 mil anos (Absy et al., 1991; Sifeddine et al., 1994; veja, entretanto, comentários críticos por Colinvaux et al., 2000: 157).

\footnotetext{
** Räsänen et al. (1995) consideraram estratos sedimentares encontrados na região superior dos Rios Purus e Acre como os do Mioceno Tardio. São necessários estudos adicionais para verificar a idade Quaternária dos estratos coletados por Kronberg et al. (l.c.) e a idade Terciária dos sedimentos estudados por Räsänen et al. (1.c.) nessa área.
} 


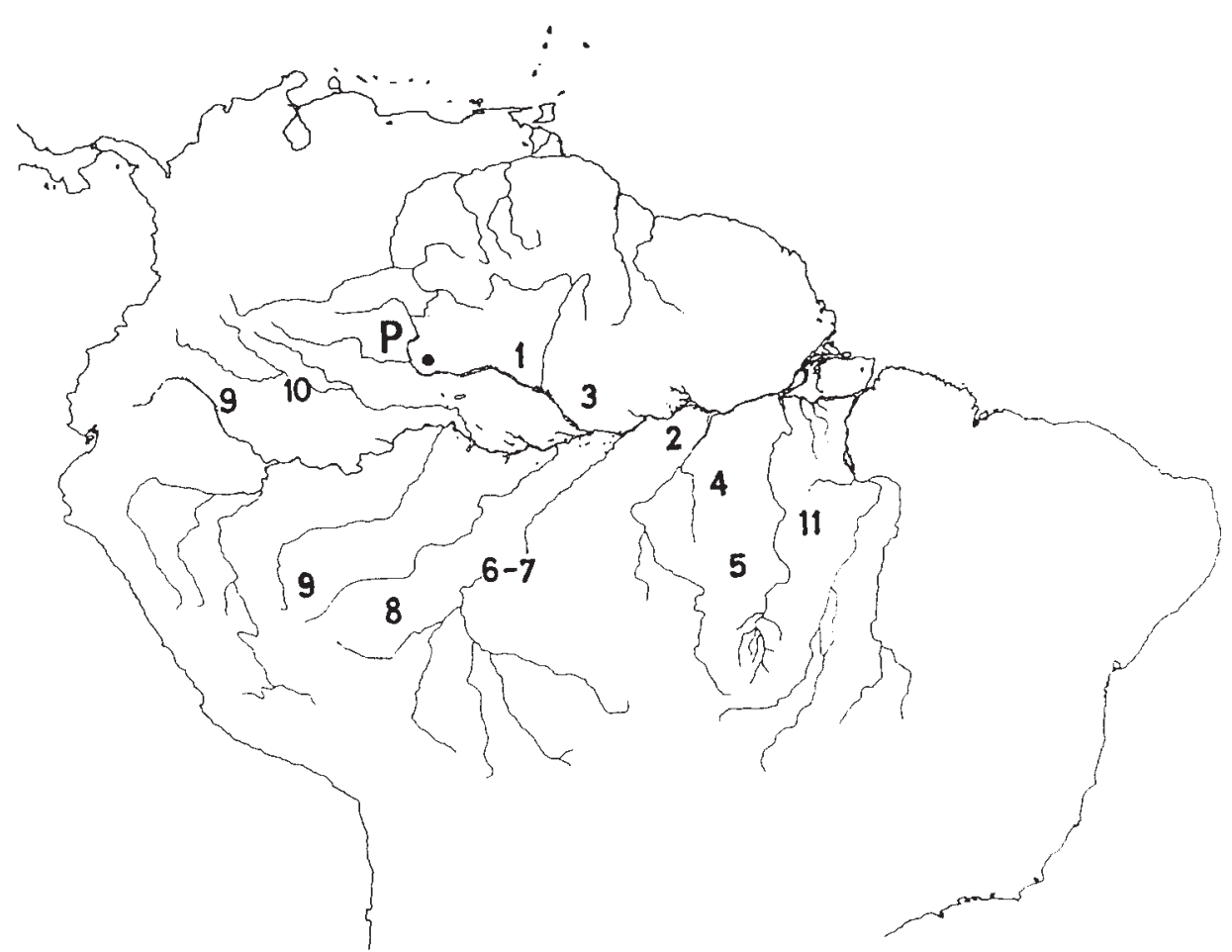

Figura 1 - Mapa com a localização das áreas da Amazônia onde foram coligidos, em anos recentes, os indícios paleoecológicos para períodos climáticos secos e mudanças da vegetação associadas ao Pleistoceno tardio (veja texto para explicação dos números). Um precioso conjunto de informações sobre as mudanças climático-vegetacionais do Quaternário está disponível para o norte da América do Sul e Brasil Central, exceto Amazônia (não indicadas neste mapa). P (ponto negro) - localização do Lago Pata.

Durante os períodos glaciais, quando o nível marinho global atingia 120 metros abaixo do atual, o lençol freático regional era mais baixo, o Rio Amazonas e as porções inferiores de seus tributários fluíam em vales encaixados, relativamente estreitos. Combinado com um clima regionalmente mais quente do atual, isso provavelmente teve um efeito severo sobre a vegetação em razão da reduzida disponibilidade de água, o que levou a mudanças muito espalhadas na composição florestal e na retração de florestas em grande parte da Amazônia Central e Inferior, onde a precipitação é principalmente por convecção e hoje em dia há uma estação seca relativamente pronunciada (Salati, 1985). De maneira semelhante, Burnham \& Graham (1999: 569) afirmaram: "Considerando que grande parte da Bacia Amazônica atualmente está próxima do nível do mar, um abaixamento desse nível, no passado recente, em cerca de 121 metros $( \pm 5$ metros) do máximo glacial deve ter tido certo efeito de dessecação sobre a vegetação em vista de flutuações no lençol freático". Os vastos campos de dunas fósseis na região de Lhanos, do leste da Colômbia-Venezuela ao noroeste da Amazônia, indicam que essa parte da América do Sul tornou-se parecida com deserto duran- 
te certos períodos do Quaternário. Clapperton (1993a) afirmou que: “A convergência dos indícios de ordem continental apóia o conceito de condições mais secas e menos cobertura de floresta fechada no máximo glacial. Os registros dos núcleos de gelo dos Andes peruanos registram um aumento de 200 vezes na poeira atmosférica durante o Último Estágio Glacial, possivelmente devido ao fato de que a cobertura florestal nos arredores da Bacia Amazônica tenha sido mais irregular do que é hoje (Thompson et al., 1995). Com referência aos baixos teores de nitrato nos núcleos de gelo, os últimos autores notaram que eles "fazem supor que a cobertura florestal fora reduzida de maneira significativa, em resposta às condições secas e à expansão de campinas" (Thompson et al., 1995: 47). Indícios geológicos e geomorfológicos adicionais para períodos climáticos secos da Amazônia e outras áreas da América do Sul tropical têm sido revistos por diversos autores como Garner (1974, 1975), Journaux (1975), Bigarella \& Ferreira (1985), Ab'Sáber \& Absy (1993), Hooghiemstra \& Van der Hammen (1998) e Behling (2001).

Apenas algumas das abordagens acima, acerca de dados indicando condições razoavelmente secas em partes da Amazônia durante determinados períodos geológicos foram levadas em consideração por Colinvaux et al. (2000) e Colinvaux \& de Oliveira $(2000,2001)$ sustentando que as florestas da Amazônia Central jamais foram afetadas por condições climáticas secas e, portanto, nunca sofreram fragmentação por vegetação intermediária e claramente aberta (veja também Jones, 2001). Por outro lado, Van der Hammen \& Hooghiemstra (2000), revisando a história da vegetação e do clima da Amazônia no Terciário Tardio e no Quaternário, estimaram que as chuvas durante o Último Máximo Glacial podem ter-se reduzido em 30-50\%, levando a uma substancial retração das florestas pluviais úmidas e à formação de refúgios florestais úmidos separados por tipos mais secos de vegetação. Também, em nenhum dos registros publicados da Amazônia e do Brasil Central há sedimentos do Último Máximo Glacial (UMG) presentes ou abundantes (Ledru et al., 1998; Van der Hammen \& Hooghiemstra, 2000 para o Lago Pata). O UMG foi representado por um hiato de vários milhares de anos ou mais, indicativo de climas mais secos do que antes e, depois, "alterações nos sedimentos atestam para climas mais secos, entre cerca de 24 mil e 17 mil YBP" (Ledru et al., 1998: 236). O clima dos Altos Andes da Bolívia e Peru era úmido durante o Último Máximo Glacial e a seqüência desse período foi caracterizada por uma sucessão de períodos muito secos; Baker et al. (2001) acreditam que esses resultados também se aplicam a grande parte da Bacia Amazônica. Por outro lado, o paleoceanógrafo Alan Mix imagina que uma anomalia de alta pressão empurrou a chuva para fora da região da floresta amazônica, propiciando dias úmidos nos Andes e secando as planícies amazônicas; isso explica as observações recentes de que os níveis de água do Lago Titicaca subiram durante o Máximo Glacial (citado em Jones, 2001: 38). De maneira semelhante, Hostetler \& Mix (1999) concluíram que "seca sazonal na simulação OSU aplica-se bem no 
interior da Bacia Amazônica e América Central", durante o Último Máximo Glacial; as terras baixas amazônicas eram substancialmente mais secas do que as indicadas antes na simulação CLIMAP. Os resultados das simulações sobre vegetação para o Último Máximo Glacial por Cowling et al. (2001) são tratadas a seguir (dentro da "hipótese da Densidade do Dossel”). A composição isotópica de oxigênio nos foraminíferos plantônicos, encontrados num testemunho de sedimento marinho em uma região de descarga do Rio Amazonas, mostra que a grande bacia regional comportou amplos espaços secos durante o frio período Dryas Mais Novo (cerca de 13 mil a 11,6 mil YBP), com a descarga reduzida em pelo menos $40 \%$ quando comparada com dados da atualidade; a umidade efetiva aumentou constantemente mais tarde, durante o Holoceno (Maslin \& Burns, 2000).

Burham \& Graham (1999: 569) concluíram sua excelente e equilibrada revisão afirmando: "Há diversas indicações de que os climas nas terras baixas neotropicais no Glacial Tardio e no início do Holoceno tiveram intervalos mais frios e mais secos e, diversamente, mantiveram um mosaico de florestas úmidas e florestas mais secas do que a vegetação do tipo savana. Eles são: 1 fósseis de faunas de mamíferos nas Américas Central e do Sul [...]; 2 uma tendência na direção de condições mais secas e um arranjo mais complexo de comunidades desenvolvendo-se próximo ao fim do Período Terciário em Costa Rica e no Panamá [...]; 3 aridez nas transições interglacial-glacial na Guatemala [...]; 4 feições geomorfológicas sugerindo aridez durante o Quaternário nas terras baixas amazônicas [...]; 5 mudanças marcantes no nível do mar [...]; e 6 aridez no Quaternário demonstrada em outras partes adjacentes e distantes do mundo [...]”.

"As combinações desses dados: temperaturas, cerca de $6{ }^{\circ} \mathrm{C}$ mais frias [durante o UMG], nível do mar, cerca de $120 \mathrm{~m}$ mais baixo e seqüências de polens indicando, pelo menos, habitats secos e vegetação aberta, são persuasivas. Elas criaram uma visão da vegetação de terras baixas neotropicais alternando entre floresta fechada e floresta aberta mais seca ou vegetação tipo savana, durante as flutuações ambientais ocorridas no Período Terciário Tardio e no Período Quaternário" (Burhnam \& Graham, 1999: 570).

\section{A teoria dos Refúgios da diferenciação biótica}

O dessecamento da América do Sul tropical, durante os períodos climáticos secos do Cenozóico, provavelmente não foi responsável pelo fato de a Amazônia Média e a Inferior perderem as florestas que foram substituídas por vegetação sazonalmente seca de savana e cerrado, como os recentes autores ilustraram em seus cenários esquemáticos para o Pleistoceno (Clapperton, 1993b; Iriondo \& Latrubesse, 1994). Tal eliminação completa das florestas pluviais seria improvável por duas razões: em primeiro lugar, qual foi a origem das florestas pluviais da Amazônia que agora são tão amplamente distribuídas? Em segundo lugar, como poderia ser explicada a origem do grande número de espécies e subespécies alopátricas na Amazônia? 
Os centros de origem de muitas dessas formas alopátricas limitam-se mutuamente ao longo das margens opostas do Rio Amazonas e seus principais tributários. Foi sugerido que essas formas teriam se originado in situ, durante o Pleistoceno ou períodos geológicos anteriores, com os rios como barreiras permitindo a diferenciação desses espécimes (teoria do Rio ou teoria da Barreira Fluvial). Porém, essa hipótese é contraditória em muitas áreas pelos fatos apresentados a seguir.

Os rios param de formar barreiras nas regiões florestadas das cabeceiras, onde as populações representativas estão em contato direto (cruzando-se por hibridação ou excluindo-se reciprocamente por imposição geográfica sem que haja hibridação). Como Wallace (1852: 110) já afirmara: "Na aproximação das fontes dos rios eles cessam de ser um limite e a maior parte das espécies é encontrada em ambas as margens". Esta situação indica uma falta de isolamento geográfico na região das cabeceiras entre populações que, sem dúvida, estão efetivamente separadas pelos amplos rios ao longo de seus cursos. A aplicação direta da teoria de especiação alopátrica para tais populações em contato com as regiões das nascentes dos rios amazônicos é impossível.

Numerosas subespécies e espécies de pássaros e outros animais da floresta pluvial amazônica confinam-se ao longo das zonas de contato secundárias distintas em contínuas regiões florestais de terra firme. Em muitos casos, seus sítios não estão relacionados com grandes rios cujas zonas de contato se cruzam em ângulos retos (fig. 2). Tais áreas de contato representam as principais zonas de descontinuidade biogeográfica, num ambiente florestal contínuo (Haffer, 1997a, 2000).

Diversos taxa representativos que habitam o interior da floresta, cujos centros de origem são separados pelos cursos dos rios (como populações uniformes e fenotipicamente não diferenciadas), ocupam extensas áreas cortadas por rios maiores do que aqueles que separam os respectivos redutos desses representativos. Análises futuras demonstrarão se tais populações fenotipicamente uniformes exibem ou não fortes diferenças genéticas.

(1) Estudos genéticos de populações de animais da Amazônia, ratos (Da Silva \& Patton, 1993), rãs (Gascon et al., 1998) e sagüis tamaris (Patton et al., 2000 ) revelaram padrões espaciais na região do Rio Juruá que não apóiam a teoria do Rio, mas são mais consistentes com uma interpretação de populações que estabeleceram contato secundário nessa região. Como foram tratadas por Patton et al. (2000) e outros autores, as relações filogeográficas de taxa habitando margens opostas de rios permitem que se faça uma distinção se tais taxa estão em contato primário ou secundário ou se ocorreu uma dispersão de um lado do rio para a margem oposta. Os exemplos mencionados acima favorecem a interpretação de contato secundário ( situação B na fig. 3) envolvendo separação em larga escala das respectivas populações durante um ou mais períodos no curso do passado geológico (seja por mudanças na vegetação ou por alterações geológicogeomorfológicas na paisagem). 
(2) A teoria do Rio conflita também com o registro geológico, porque muitas das espécies alopátricas hoje ocorrem em áreas que eram presumivelmente secas e desflorestadas ou ligeiramente florestadas durante certos períodos climáticos do passado.

Entretanto, o modelo da Barreira Fluvial mostra-se aplicável para uma interpretação de subespeciação e talvez, também, de especiação em sagüis do gênero Callithrix (Roosmalen et al., 2000) e, possivelmente, em certos pássaros (Haffer, 1992) da região dos Rios Madeira-Tapajós-Xingu no sudeste da Amazônia. Os rios de curso reto e seus tributários nessa área fluem pelo declive relativamente íngreme do norte do Escudo Brasileiro, que impede a formação de meandros e, com isso, o transporte passivo de populações de animais sedentários por meio do corte do pedúnculo dos meandros. As populações de sagüi do gênero Callithrix nos vários interflúvios são bem diferenciadas na cor da pelagem. Todavia, permanece desconhecida a maneira pela qual formas visivelmente diferentes passam gradualmente a outras (subespécies) nas regiões das nascentes e como sobrepõem seus redutos sem hibridação (espécies).

A teoria dos Refúgios (Haffer, 1969, 1974, 1982; Vanzolini \& Williams, 1970; Vuilleumier, 1971; Vanzolini, 1973; Müller, 1973; Prance, 1973, 1982A; Brown et al., 1974; Simpson \& Haffer, 1978; Brown \& Ab’sáber, 1979) foi proposta como uma alternativa à hipótese da Barreira Fluvial e postula a persistência de extensas manchas de florestas tropicais úmidas naquelas partes das terras baixas amazônicas, onde havia superfícies rebaixadas para criar gradientes de chuva durante as fases geralmente secas do Cenozóico (Terciário e Quaternário), próximas dos Andes, ao longo de declives de muitas montanhas ao sul da Venezuela e das Guianas, bem como ao norte do Planalto dos Parecis, no Brasil Central e perto do Oceano Atlântico, no leste do Pará. É provável que o tamanho dessas manchas de floresta úmida durante os períodos secos fosse maior e bem menos definido do que é mostrado em muitos mapas que ilustram a localização de refúgios na floresta pluvial amazônica. O fundamental para o modelo dos Refúgios é a postulada fragmentação da floresta pluvial amazônica em certo número de blocos de florestas úmidas não de maior ou menor tamanho dessas manchas de floresta pluvial durante os picos de várias fases climáticas secas. Os "Refúgios" de floresta úmida são admitidos como tendo sido separados por vários tipos de savana, floresta seca, floresta de lianas e outros tipos intermediários de vegetação de climas sazonalmente secos, que podem ter funcionado como efetivas barreiras para a dispersão de plantas e animais da floresta pluvial úmida. Segundo este modelo, os Refúgios representam áreas relativamente estáveis ao longo do tempo, localizadas em partes periféricas da Amazônia, nas quais aconteceu a recolonização das terras baixas da Amazônia Central, com a volta de condições climáticas úmidas. Aqui as espécies “acumularam” a expansão de "áreas ecotonais" da região. A teoria dos Refúgios permanece como modelo de trabalho em razão de os dados geológico-palinológicos da Amazônia serem ainda insuficientes para 
provar a fragmentação da região de floresta pluvial úmida por tipos de vegetação intermediária e seca durante períodos secos individualizados (os quais podem ou não coincidir com as fases climáticas mais frias).

A primeira prova para a existência continuada de florestas úmidas numa dada região durante o Último Máximo Glacial foi fornecida recentemente por Colinvaux et al. (1996) num longo registro de pólens de uma área no Norte do Brasil que foi um dos refúgios florestais originais proposto por Haffer (1969; Refúgio de Imeri). O testemunho de sedimento do qual foram extraídos os espectros de pólen foi coletado do fundo do Lago Pata (fig. 1), localizado a apenas 60 quilômetros a sudoeste da montanha da Neblina-Imeri, área que atinge a altitude de 3 mil metros na região fronteiriça entre o Brasil e a Venezuela. O registro de pólen do Lago Pata do Último Máximo Glacial indica, para aquele período, a existência nessa região de floresta pluvial tropical, a qual, entretanto, também incluía alguns taxa de plantas que hoje estão confinados a níveis inferiores da montanha. O registro do Lago Pata estabeleceu o fato de que, nas terras baixas circunvizinhas da Serra da Neblina-Imeri, sem dúvida existiu floresta pluvial durante a última fase glacial geralmente seca (como fora prenunciado pela teoria dos Refúgios; o Lago Pata está localizado na porção periférica sul da área pontilhada contornando o Refúgio de Imeri na figura 5 de Haffer (1969), a qual, naturalmente, pode ter sido bem mais extensa do que está indicado esquematicamente naquele esboço). Hooghiemstra \& Van der Hammen (1998: 157), Burham \& Graham (1999: 568) e Van der Hammen \& Hooghiemstra (2000) também chamaram a atenção de que o Lago Pata está localizado em uma área anteriormente prenunciada como tendo sido úmida durante o Último Máximo Glacial, considerado geralmente seco (veja Van der Hammen \& Absy 1994). O registro do Lago Pata, valioso como é o dado desse campo, não pode ser usado como critério para distinguir entre a teoria dos Refúgios e a da Perturbação da Vicariância, como foi feito por Colinvaux et al. (1996, 2000) e Colinvaux \& De Oliveira $(2000,2001)$.

No Equador, dados de pólen fóssil são disponíveis somente dos declives orientais dos Andes, a cerca de 1,1 mil metro de altitude, isto é, acima das terras baixas amazônicas, indicando que, durante o último período glacial, existiram nessa região florestas úmidas com elementos andinos (Colinvaux 1993, Colinvaux et al., 1997; veja também os comentários de Heine, 1994). Esses sítios andinos estão localizados a cerca de 500 metros mais elevados do que (e não no interior) o renomado refúgio florestal Napo das terras baixas do Equador, próximo ao piemonte das montanhas. Estudos palinológicos futuros, provavelmente, provarão a existência de floresta pluvial fechada durante as fases climáticas geralmente secas do Pleistoceno em outros setores da Amazônia, por exemplo, próxima dos Andes no sudeste do Peru, na Amazônia Sul-Central e ao sul da desembocadura do Rio Amazonas. Essas florestas do Pleistoceno eram consideradas "tropicais", porque eram habitadas por faunas das terras baixas tropicais, embora a composição das espécies vegetais possa ter mudado em certa extensão. 


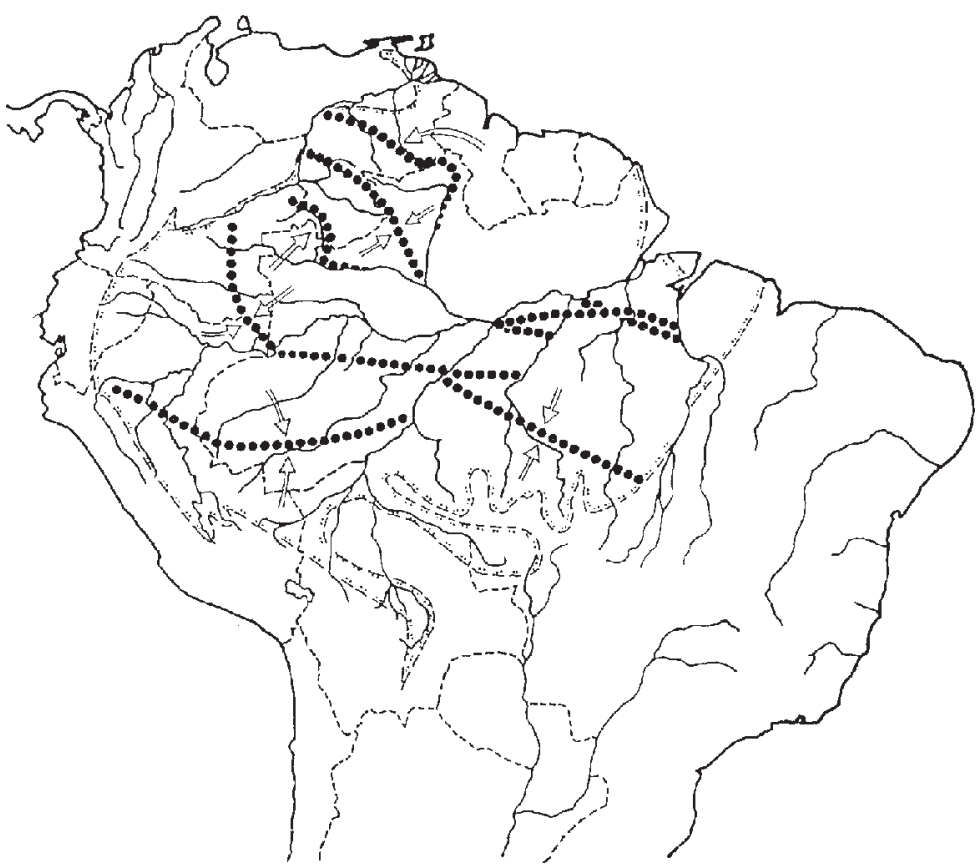

Figura 2 - Zonas de contato entre taxa de pássaros selecionados da Amazônia cujas localizações são independentes ou variavelmente deslocadas pelo curso dos rios. Outras zonas de contato seguem o Rio Amazonas e as porções inferiores dos principais tributários (de Haffer, 1997a, 2000).

A teoria dos Refúgios propõe que as mudanças na vegetação seguiram reversões climáticas em virtude dos ciclos de Milankovitch durante algum período da História da Terra, causando a fragmentação dos centros de origem das espécies e o isolamento de uma parte das respectivas biotas em refúgios ecológicos separados entre si, onde populações de espécies l se extinguiram, 2 sobreviveram sem alteração, ou 3 diferenciaram-se ao nível de subespécies ou espécies (de acordo com a teoria da especiação geográfica, Mayr, 1942, 1963). Espécies recentemente diferenciadas provavelmente sobreviveram a muitos períodos de mudança ambiental antes de nova especiação. Nós enfatizamos que a teoria não se restringe ao Pleistoceno, mas aplica-se também à diferenciação biótica durante o Cenozóico e, mais cedo (como durante o Quaternário), quando os ciclos de Milankovitch causaram oscilações no nível do mar, alterações rítmicas nas fácies de estratos geológicos e mudanças climático-vegetacionais nos continentes (Herbert \& Fischer, 1986; Olsen, 1986; Bartlein \& Prentice, 1989; Berger et al., 1989; Zachos et al., 1997, 2001; Bennett, 1997). Há evidências de que muitas espécies que ainda existem já haviam se isolado durante o Plioceno, quando podem ter originado, no decorrer do Terciário, refúgios florestais. A teoria dos Refúgios se refere à postulada origem das espécies e subespécies em refúgios ecológicos (florestais e não-florestais) nos continentes, independentemente dos períodos de tempo, isto é, durante todo o Cenozóico ou até antes (Haffer, 1993). 

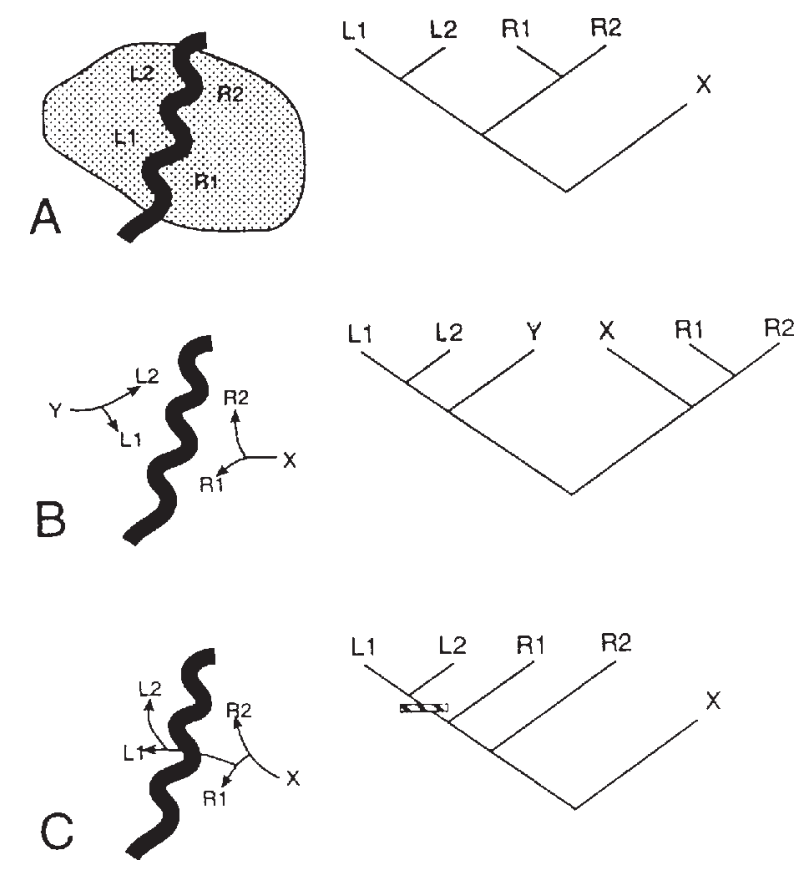

Figura 3 - Três hipóteses filogeográficas alternativas. A: Diversificação primária: clados reciprocamente monofiléticos e irmãos limitados por um rio que se impôs sobre um centro de origem das espécies existentes. B: Contato secundário: clados reciprocamente monofiléticos, mas não irmãos, limitados por um rio que serviu como ponto de encontro secundário dos clados que se desenvolveram alhures. C: Dispersão: parentesco parafilético de haplótipos da margem direita em relação aos da margem esquerda, devido a um episódio de transferência no cruzamento dos rios. De Patton et al. (2000).

Para Bennett (1997: 185), é razoável considerar eventos durante o Quaternário como representativos das escalas de tempo de 20 mil a 10 mil anos ao longo da História da Terra. Rupturas de comunidades e especiação em populações geograficamente isoladas, criadas pelas mudanças ambientais perpétuas das escalas de tempo de Milankovitch, têm sido uma característica permanente, embora normalmente não reconhecida em vista da resolução relativamente grosseira da maioria dos registros geológicos e paleontológicos.

Devem ser levados em consideração alguns cuidados com a aplicação da teoria dos Refúgios: as florestas de galeria promovem fluxo gênico entre refúgios e, provavelmente, a redução do total de diferenciação; apenas espécies florestais ecológica e restritamente adaptadas foram afetadas, ao passo que é pouco provável que populações de espécies ecologicamente mais flexíveis tenham, efetivamente, sido isoladas em refúgios.

Indícios biogeográficos que apóiam a teoria dos Refúgios incluem a coincidência de áreas de endemismo em diferentes grupos de organismos (fig. 4) e a ocorrência bem definida de zonas de contato entre certas espécies e subespécies de pássaros florestais da Amazônia que representam zonas de distinta desconti- 
nuidade biogeográfica num ambiente florestal contínuo (fig. 2). Ron (2000) e Bates (2001) estudaram cladisticamente as áreas de endemismo de diferentes grupos vegetais usando a Análise de Parcimônia da Endemicidade para produzir hipóteses dos parentescos de área. Os três grupos até hoje conhecidos são: Belém, Guiana e Amazônia Superior (Napo+Inambari). No caso de zonas de hibridação entre subespécies, essas áreas têm duas características que ocorrem em faixas nas quais as populações estabeleceram contato secundário, após um período de separação: populações na zona de hibridação têm variabilidade bastante aumentada; e fora da zona de hibridação, as duas formas são, em áreas amplas, relativamente uniformes, quando muito variando gradualmente (clinally) ao longo de grandes distâncias. Evidência adicional é suprida por taxa de pássaros florestais restritos a uma ou duas regiões florestais localizadas na Amazônia, mas ausentes em outros lugares e taxa com distribuição disjunta (Haffer, 1974, 1997b; Mayr \& O'Hara, 1986). Diversos outros autores observaram fenômenos biogeográficos similares e os interpretaram de maneira correspondente para plantas (Prance, 1973, 1982a, 1987, 1996), répteis (Vanzolini \& Williams, 1970; Vanzolini, 1992), peixes (Huber, 1998), borboletas (Brown, 1976, 1987b; Brower, 1996), e mamíferos (Cerqueira, 1982). Podemos mencionar também as estreitas relações entre certas faunas não-florestais e elementos da flora das áreas ao norte e ao sul da Amazônia e que requerem conexões temporárias ao longo dessas terras baixas florestadas.

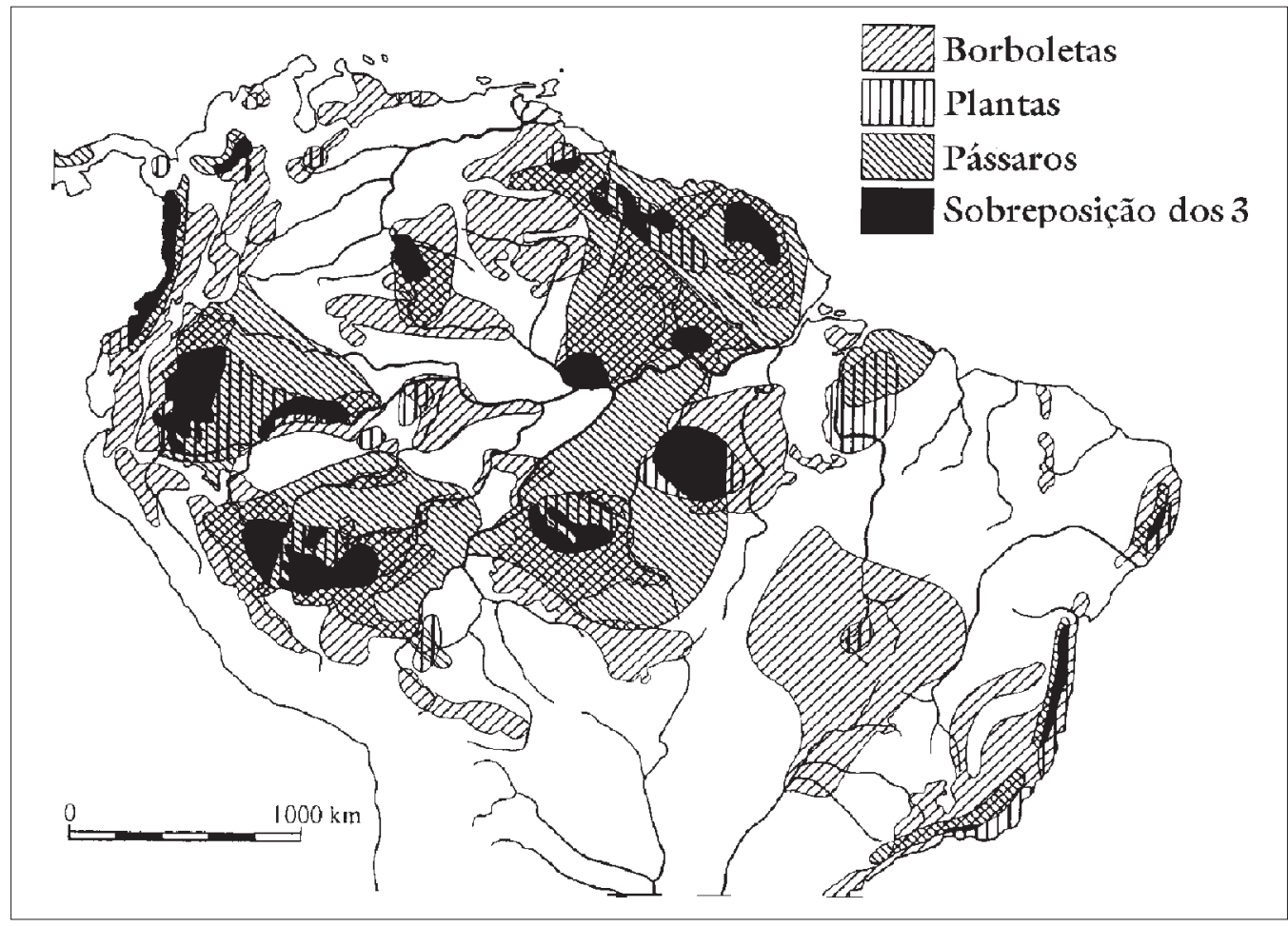

Figura 4 - Sobreposição de padrões de endemismo em plantas, borboletas e pássaros do Neotrópico. Adaptado de Brown (1987c). 


\section{Noções errôneas sobre a teoria dos Refúgios}

Dentre as diversas concepções erradas sobre o modelo dos Refúgios para a Amazônia, encontradas em literatura recente, incluímos as seguintes (referências em Haffer, 1993).

- Esse modelo foi supostamente baseado apenas nos padrões bióticos atuais; ele foi desenvolvido combinando conjuntos de dados de duas fontes independentes. Um conjunto de dados envolve informações de paleobotânica, geomorfologia e extrapolações climáticas. O segundo vem de análises de padrões modernos de distribuição de animais e plantas. A partir de cada conjunto analisado independentemente, foi possível fazer previsões acerca da distribuição de florestas de terras baixas durante as fases climáticas secas do Pleistoceno. A coincidência entre a localização de presumidos refúgios florestais derivados desses dois conuntos independentes de dados conduziram à formulação da teoria geral (Simpson \& Haffer, 1978).

- O modelo dos Refúgios se refere a um único evento de vicariância do Pleistoceno Tardio. Na realidade, uma série de reversões climático-vegetacionais e eventos associados de vicariância durante o curso de todo o Quaternário foram reunidos na hipótese de ter causado diferenciação biótica (Haffer, 1969; "Nos últimos 2 milhões de anos a floresta parece ter passado por repetidos episódios de contração e expansão", Simpson \& Haffer, 1978: 513).

- O modelo dos Refúgios aplica-se supostamente apenas ao Pleistoceno. Na realidade, a teoria refere-se também ao Terciário e a períodos anteriores (Haffer, 1993 e veja acima).

- Toda evolução da biota neotropical provavelmente ocorreu nos refúgios do Quaternário e todas as espécies que ainda existem datam do Quaternário. Nenhum autor jamais fez tais alegações.

- As regiões entre os postulados refúgios florestais úmidos eram supostamente cobertas apenas por savanas de herbáceas. Na realidade, foi especulado que "provavelmente havia florestas adicionais menores ao longo dos cursos dos principais rios da Amazônia, nos declives de montanhas isoladas e nas extensas terras baixas entre o Rio Madeira superior e o Rio Marãnón" (Haffer 1969: 134). "Certos tipos de vegetação, tais como floresta seca, floresta de transição, floresta de lianas e floresta de bambus teriam bloqueado a distribuição de muitas espécies e devem ter sido igualmente eficientes como uma causa de vicariância", por exemplo, savanas ou cerrados (Prance, 1981: 400). "Entre as áreas isoladas úmidas, onde a floresta pluvial persistiu, deveria ter existido um mosaico complexo de diferentes tipos de vegetação de climas sazonalmente secos que teriam sido uma efetiva barreira para a dispersão da maioria das plantas e animais da floresta pluvial" (Brown, 1987a: 43). 
- Cada período de formação de refúgio supostamente conduziu sempre à plena especiação nas populações separadas. Na realidade, isso é improvável e nunca foi sugerido por autor algum.

- Todas as espécies recentemente diferenciadas se dispersaram bastante das áreas dos antigos refúgios quando voltaram às condições úmidas. Na realidade, muitas espécies endêmicas têm hoje distribuições muito restritas.

- Durante os tempos glaciais supostamente não existiram refúgios florestais em terras baixas na América Central, cuja região foi recolonizada pela expansão da floresta pós-glacial a partir dos distantes refúgios da América do Sul. Nenhum autor jamais fez tais alegações. Realmente, a provável existência de uma série de refúgios florestais nas terras baixas do Pacífico e do Caribe, próximos às áreas montanhosas da América Central, vem sendo analisada há mais de 30 anos.

A lista acima indica que muitos argumentos imaginários e inconsistentes têm sido usados na literatura recente para criticar a teoria dos Refúgios.

\section{História da teoria dos Refúgios}

A teoria da especiação nos refúgios ecológicos foi desenvolvida originalmente por Edward Forbes em 1846 (conforme foi mencionado por Mayr \& O'Hara, 1986) e foi depois aplicada por Stresemann (1919), Stresemann \& Grote (1929) e diversos autores nos anos de 1930, que estudaram a origem de membros intimamente relacionados entre casais de espécies de aves do norte da zona temperada e da África tropical.

Autores de obras de zoogeografia geral indicaram a importância do repetido aparecimento e desaparecimento de barreiras de vegetação para o processo de especiação e subseqüente irradiação adaptativa em muitos grupos de organismos tropicais e de alta latitude (Mayr 1942, 1963: 561; Darlington, 1957).

A seguir, a teoria foi aplicada às avifaunas da Austrália (Keast, 1961; Joseph et al., 1995; Williams \& Pearson, 1997; Schneider et. al., 1998), à África tropical (Moreau, 1966; Crowe \& Crowe, 1982; Vrba, 1995; Lévèque, 1997), à região neotropical (Haffer, 1969, 1974; Vanzolini \& Williams, 1970, 1981; Vuilleumier 1971, Vanzolini, 1973; Prance, 1973; Müller, 1973; Prance, 1982a,b), ao arquipélago malaio (Brandon-Jones, 1996, 1998 [primatas]) e à Nova Guiné (Pratt, 1982, Beehler et al., 1986: 21).

Estudos filogeográficos modernos têm confirmado esta visão dinâmica de biogeografia global durante os últimos milhões de anos (Hewitt, 2000; Avise, 2000). O modelo dos Refúgios para a Amazônia (e outras regiões tropicais do mundo) permanece uma hipótese de trabalho viável até que os testes se tornem possíveis, quando os dados palinológicos, geológicos e geomorfológicos dessa região estiverem disponíveis nas próximas décadas, em particular das regiões de terra firme da Amazônia Central e a certa distância dos grandes rios. 


\section{Modelos alternativos de especiação alopátrica}

Hipótese da Densidade do Dossel. Pesquisa recente investigou possíveis respostas da vegetação das terras baixas amazônicas ao clima do Último Máximo Glacial (UMG), enfocando o balanço entre mudanças no tipo e estrutura da vegetação (Cowling et al., 2001). A maior parte dos $20 \%$ simulados de decréscimo na cobertura florestal durante o UMG ocorreu próxima às margens sul da bacia e diversas regiões localizadas de tipo de vegetação xérica foram introduzidas na Amazônia Central. Os resultados também sugeriram reduções e acréscimos repetidos na densidade do dossel florestal sobre grandes áreas durante os ciclos glacial e interglacial. Alterações no microclima do dossel foram provavelmente causadas pelo resfriamento glacial, aridez e baixas concentrações de gás carbônico, levando a mudanças individualizadas na distribuição de espécies animais e vegetais. Durante os períodos glaciais, as florestas com reduzida umidade nas copas e temperaturas relativamente altas provavelmente tiveram uma distribuição mais ampla do que hoje, o que deve ter levado a uma interrupção no fluxo gênico (vicariância) em muitas espécies e, subseqüentemente, na especiação. Segundo essa hipótese, a separação biológica do conjunto de genes não exige, necessariamente, fragmentação florestal, mas apenas uma mudança de florestas úmidas para secas.

A hipótese da Densidade do Dossel não se aplica apenas ao Pleistoceno mas também a períodos bem anteriores no Cenozóico, pelo fato de as florestas serem independente e interativamente influenciadas por decréscimos na temperatura, precipitação e teor de gás carbônico na atmosfera. Reconstruções paleoclimáticas indicam que teores relativamente baixos de gás carbônico e temperaturas altas poderiam ter resultado em grandes variações espaciais na vegetação florestal, isolando espécies geograficamente desse modo ao longo do tempo.

Essa teoria não é muito diferente da hipótese dos Refúgios. Ambos os modelos propõem que ocorreram mudanças em larga escala na vegetação da Amazônia, durante períodos de mudanças climáticas (precipitação, temperatura, gás carbônico) levando a uma expansão de vegetações florestais e não-florestais adaptadas à seca. Ambos os modelos referem-se não apenas ao Pleistoceno mas também a períodos geológicos mais velhos. Baseada em dados geomorfológicos de campo da Amazônia Central e de ampla distribuição de plantas de savana, a hipótese dos Refúgios dá ênfase, principalmente, à ocorrência de larga distribuição de vegetação aberta na Amazônia, durante períodos climáticos secos, enquanto as simulações de Cowling et al. (2001: 142) introduziram somente "umas poucas regiões localizadas de tipos de vegetação xérica" no interior da Amazônia Central. Todavia, em vista do fato de que, segundo a hipótese dos Refúgios não apenas zonas de vegetação aberta mas também regiões cobertas com vários tipos de floresta seca e outros tipos intermediários de vegetação atuaram como barreiras para animais umbrófilos de florestas úmidas, ambas hipóteses têm mais semelhanças do que diferenças. 
Colinvaux (1998) apresentou outro modelo de vicariância de especiação na Amazônia, a hipótese da Perturbação da Vicariância. Ele acredita que, durante os períodos glaciais do Pleistoceno, os sítios ligeiramente elevados dos postulados refúgios florestais nas regiões periféricas da Amazônia realmente representraram frio, "ilhas" deficientes de gás carbônico num "mar" de contínuas florestas tropicais de terras baixas, ao inves de "ilhas" florestais úmidas num "mar" de tipos de vegetação bem aberta e intermediária. No entanto, as considerações seguintes são argumentos contra essa hipótese: 1 é improvável que a diferença na altitude de 100 a 200 metros entre as planícies que margeiam os rios e as áreas periféricas dos refúgios (e as diferenças associadas na média de temperatura e teor de gás carbônico) tenham efeito tão forte sobre a biota como alegou o autor; 2 os numerosos registros paleontológicos de muitas regiões da Amazônia tratados acima e a distribuição atual de muitas espécies de plantas de savana indicam que condições climáticas secas eram amplamente espalhadas durante vários períodos do Pleistoceno; com exceção de raríssimos registros palinológicos, pequena parte dessa informação foi levada em conta por Colinvaux; 3 este modelo de vicariância aplica-se apenas aos períodos climáticos do Pleistoceno com alternância frio-quente, mas não explica o mecanismo de especiação na Amazônia e outras regiões dos trópicos durante o muito longo e quente período Cenozóico, quando também devem ter ocorrido diferenciações bióticas muito ativas (e se originou a maior parte das espécies que ainda existem), devido provavelmente ao efeito das fases climáticas úmidas e secas causadas pelos ciclos de Milankovitch do pré-Quaternário. Assim, a teoria do Refúgio (concernente a todo o Cenozóico) e a teoria da Perturbação da Vicariância (referente apenas ao Quaternário) não são alternativas.

Bush (1994) também afirmou que o resfriamento climático, ao contrário da aridez, foi o fator que dirigiu um rearranjo da vegetação na Amazônia durante o Pleistoceno. Contudo, ele aceitou o dessecamento climático (de cerca de 20\%) através da Amazônia durante os períodos glaciais, o que levou à expansão de tipos de vegetação adaptados à seca nos cinturões climáticos transversais, cruzando a Amazônia Inferior (central) de sudeste a noroeste e cruzando também o sudoeste da Amazônia, ao longo da região limítrofe entre o Peru e o Brasil (fig. 3). Dessa maneira, ele aceitou a separação de blocos da floresta pluvial úmida nas Guianas e na desembocadura do Rio Amazonas, das florestas da Amazônia Superior, bem como a separação de florestas de terra baixa ("refúgios") ao longo da base dos Andes peruanos, das extensas florestas da Amazônia Superior. Aparentemente, Bush tinha em mente refúgios de espécies características, quando asseverou: "Se as espécies individuais vivendo sob condições de resfriamento e dessecamento, se estressaram a ponto de extinção em par-tes de seus centros de origem e apenas sobreviveram em áreas que lhes foram ótimas, surge aí um mecanismo para especiação alopátrica". Essa é uma extensão da hipótese de Colinvaux de perturbação da vicariância, que se baseia na premissa de que a floresta da Amazônia Central provavelmente não era marcadamente fragmentada (Colinvaux 
1993, 1996). Ambos, Colinvaux (1.c.) e Bush (1.c.) sugeriram que áreas do mais elevado endemismo específico em regiões periféricas da Amazônia são locais de perturbação máxima (ao invés de estabilidade florestal máxima em refúgios florestais); essa conjetura é improvável e requer reexame (Morley 2000: 129, 279).

Colinvaux et al. (2000) revisaram os registros palinológicos em três áreas na Amazônia e em um local de amostragem na costa e concluíram que nenhuma porção da Amazônia jamais experimentara climas secos durante certos períodos do Quaternário. Seu banco de dados dessa vasta região é claramente insuficiente para chegar à tão arrojada conclusão. Além disso, esses autores não levaram em consideração muitos dados geomorfológicos indicando climas secos e vegetação aberta, como foi dito acima, nem os remanescentes (refúgios atuais) de plantas de savana. Com relação aos resultados de análises de pólens de testemunhos de sedimentos marinhos vindos de fora da desembocadura do Rio Amazonas (Haberle \& Maslin, 1999), há diversas razões para pôr em dúvida o valor da evidência polínica como foi examinada por Hooghiemstra \& Van der Hammen (1998): 1 grãos de pólen de gramíneas podem ser derivados de vegetação tipo savana ou de campinas (campestres) flutuantes, ricas em gramóneas; 2 mistura e redeposição de sedimentos durante stands glaciais do nível do mar, os quais estavam a cerca de 120 metros mais baixos do que hoje; 3 as grandes florestas de galeria ao longo dos cursos dos rios na Amazônia provavelmente evitaram que grãos de pólen da vegetação de savana atingissem o sistema fluvial. Admite-se que a vegetação de savana esteja pobremente representada no espectro de pólen transportado pelo rio. Segundo Hooghiemstra \& Van der Hammen (1998) e Van der Hammen \& Hooghiemstra (2000), as conclusões de Colinvaux et al. (1996, 2000) com respeito à cobertura de floresta pluvial estável da Amazônia desde o último período interglacial são injustificadas.

Hipótese do Museu. Fjeldså et al. (1999: 63, 76) associaram a origem de novas espécies com áreas muito restritas e ecologicamente bastante estáveis nos piemontes de regiões montanhosas, ao redor da Amazônia, de onde novas espécies supostamente se espalharam nos níveis de base das planícies e aí se "acumularam" ao longo do tempo. Os últimos autores são da opinião que "a especiação em pássaros florestais pode não requerer necessariamente o desenvolvimento de grandes "barreiras" de habitats não-florestais (como é admitido pela teoria dos Refúgios). Um pássaro adaptado poderia também desaparecer ao longo de grandes áreas em razão do aumento da reposição de espécies resultante da alta heterogeneidade funcional de habitats. Tais modelos, mesmo plausíveis do ponto de vista teórico, são contestados pela evidência geocientífica de ampla ocorrência de mudanças na vegetação em toda a Amazônia durante os períodos climáticos alternados entre secos e úmidos do Quaternário e, provavelmente, nos períodos anteriores.

Hipótese Paleogeográfica. O cenário paleogeográfico comparativamente simples da bacia amazônica, entre o Escudo da Guiana para o norte e o Escudo Brasileiro para o sul, durante o período Cenozóico (de 60 milhões de anos de dura- 
ção), não parece ter proporcionado um teatro geológico suficientemente complexo e de rápidas mudanças para causar as intensas evolução, diferenciação ecológica e especiação na flora e fauna de terras baixas, e que certamente ocorreram lá durante aqueles tempos. Essa situação paleogeográfica, como foi tratada e ilustrada por Harrington (1962) e Petri \& Fúlfaro (1983), pode ter proporcionado não mais do que uma armação básica para que a evolução se efetivasse. Lembra bem as flutuações climático-vegetacionais causadas pelos ciclos de Milankovitch, levando a freqüentes vicariâncias ecológicas com as mudanças da vegetação nessas regiões terrestres (Escudo da Guiana, Escudo do Brasil, piemontes das montanhas andinas), e causando mais uma pronunciada especiação e evolução do que por meio de variações costeiras de terra e mar. Nos anos recentes têm sido publicados muitos cladogramas para espécies de gêneros e famílias de animais e plantas sul-americanos, ilustrando numerosos ramos de linhagens evolucionárias durante o curso do Terciário, geralmente sem análises da provável natureza dos eventos de vicariância que apoiaram tais eventos cladogenéticos (que em muitos casos podem ter sido causados por vicariância ecológica). Nores (1999) e Bates (2001) são de opinião que o desenvolvimento paleogeográfico da maior região amazônica incluiu suficientes eventos de vicariância para explicar a complexa diferenciação da fauna neotropical (basicamente sem mecanismos adicionais requeridos para vicariância de populações). Desse modo, esses autores relacionaram a origem de espécies e subespécies de pássaros que ainda existem com a separação dos frontais andinos, o Escudo da Guiana e o Escudo do Brasil, por incursões marinhas há cerca de 2 a 4 milhões de anos (hipótese "insular").

Deveria ser advertido que a elevação das montanhas dos Andes nos tempos do Oligoceno e do Mioceno criou uma importante barreira entre as terras baixas trans e cis-andinas, embora muitos elementos amazônicos fossem capazes de invadir as florestas pluviais colombianas do Pacífico e da América Central via planícies do norte da Colômbia, durante os períodos geológicos posteriores.

Outros modelos de especiação alopátrica que têm sido propostos para a Amazônia nos últimos anos incluem a hipótese dos "Refúgios do Rio", a hipótese do "Lago" e a hipótese do "Arco". Todavia, pouco suporte geológico pode ser aduzido a qualquer desses modelos. Segundo a hipótese dos Refúgios do Rio, as populações de plantas e animais foram presumivelmente isoladas por uma combinação dos amplos cursos de rios amazônicos inferiores e extensas áreas nãoflorestadas ou pobremente florestadas nas regiões de cabeceiras do norte e do sul da Amazônia durante períodos climáticos secos, quando a zona de florestas tropicais supostamente se contraiu em direção ao Equador em extensas frentes latitudinais, deixando a Amazônia Central intocada (Ayres \& Clutton-Brock, 1992). Contudo, é provável que também porções da Amazônia Central tenham sido influenciadas por flutuações climáticas.

A hipótese do Lago baseia-se na presunção de que a maior parte da Amazônia era coberta por um imenso lago ou lagoa no fim do Terciário (Plioceno); 
sucessivamente, presume-se, porções menores da Amazônia foram cobertas durante uma série de elevados stands de nível do mar no decurso do Quaternário, como parece estar documentado pelos correspondentes níveis de terraços no baixo vale do Amazonas (Klammer 1984; Marroig \& Cerqueira 1997). Os proponentes desse modelo admitem que a inundação empurrou as florestas tropicais para regiões periféricas da bacia amazônica onde, além disso, os rios alargados separaram populações de animais e plantas em "ilhas" florestais. Todavia, os níveis dos terraços da Amazônia inferior provavelmente foram levantados tectonicamente à sua altura atual e não devido aos altos níveis de água na Amazônia (Clapperton, 1993b: 59).

A hipótese do Arco propõe que certas (desconhecidas) expressões superficiais de diversos elementos tectônicos cruzados ou "arcos" (ligeiras estruturas dômicas em profundidade que subdividiram a bacia amazônica em diversas subbacias estruturais), que pretensamente separariam os centros de origem de espécies de plantas e de animais, permitindo assim, sua diferenciação (Patton et al. $1997,1998,2000)$. Nós enfatizamos que os resultados dos últimos autores na região do Rio Juruá, no sudoeste da Amazônia, contestam apenas as previsões da hipótese da Barreira Fluvial e são mais consistentes com uma interpretação de populações em contato secundário hoje nessa região. Esse contato pode ser explicado com base na hipótese dos Refúgios ou na hipótese teoria do Arco (das quais Patton et al. preferiram a última). $\mathrm{O}$ arco de Iquitos, relacionado por esses autores, originou-se através de movimentos tectônicos durante o período Jurássico. Ao contrário dos arcos geológicos nos frontais andinos próximos, esse arco dificilmente estava ativo durante a deposição das formações do Cretáceo e do Terciário (veja outra apreciação em Haffer, 1997b). Permanece ainda desconhecida se a posição das zonas de contato entre pequenos mamíferos da região de Juruá segue a extensão norte-sul do arco de Iquitos na profundidade, como admitiram Patton et al. (2000) ou alguma outra direção. As zonas de contato entre membros de diversos pares de taxa representativos de pássaros encontrados na mesma região geral do Rio Juruá superior (por exemplo, Neomorphus geoffroyi, N. pucheranii e Pipra fasciicauda, P. filicauda) estenderam-se numa direção leste-oeste (fig. 2), isto é, mais ou menos perpendicular à posição do arco de Iquitos na profundidade (com a qual a origem desses taxa e suas zonas de contato muito provavelmente não têm qualquer relação).

Nós ressaltamos que as várias hipóteses mencionadas acima têm significâncias (poderes explanatórios) muito diferentes como modelos de especiação para a Amazônia. O poder explanatório é alto nos casos da hipótese paleogeográfica, da hipótese dos Refúgios e da hipótese da Densidade do Dossel por se refirirem a uma longa extensão de tempo (Terciário e Quaternário e antes) e os eventos recorrentes da formação de barreira (mudanças repetidas na distribuição de terra e mar e dos tipos de vegetação úmidos e secos sobre áreas terrestres). O poder explanatório é baixo no caso daquelas hipóteses que se referem a eventos históri- 
cos únicos (por exemplo, a origem do sistema fluvial amazônico) ou a uma curta extensão de tempo geológico, como Pleistoceno somente depois que muitas ou a maioria das espécies ainda existentes se originaram (como é o caso da hipótese da Perturbação da Vicariância).

\section{Conclusão}

Parece provável que na Amazônia e em outras regiões tropicais do mundo, a distribuição e a composição de espécies das florestas úmidas e secas, bem como de biomas não-florestais, mudaram continuamente durante o Cenozóico e no período anterior. A floresta úmida foi fragmentada em blocos isolados que depois coalesceram sob variadas condições climáticas. Devido ao efeito dos ciclos de Milankovitch, florestas úmidas e refúgios não-florestais formados provavelmente durantes os picos (frio-) seco e (quente-) úmido de fases climáticas levaram à "reposição por pulsações" na evolução de floras e faunas durante o QuaternárioTerciário e períodos anteriores (Vrba, 1992, 1993).

Referências bibliográficas

AB'SÁBER, A. N. “The paleoecology of Brazilian Amazonia” in: PRANCE, G.T. (ed.). Biological diversification in the tropics. Nova York: Columbia Univ. Press, 1982, p. 4149, 714 p.

AB'SÁBER, A.N. \& M. L. ABSY. "Paleoclimas da Amazonia”. Ciência Hoje, 16, São Paulo, p. 1-3 e 21-51, 1993.

ABSY, M. L., CLEEF, A., FOURNIER, M., MARTIN, L., SERVANT, M., SIFEDINE, A., FERREIRA DA SILVA, M., SOUBIES, K., TURCQ, K. \& T. VAN DER HAMMEN. "Mise en évidence de quatre phases d'ouverture de la forêt dense dans le sud-est de l'Amazonie au cours des 60.000 dernières années". Première comparaison avec d'autres régions tropicales. C.R. Acad. Sci. Paris, 312(2), p. 673-78, 1991.

ANDERSON, A. B. "White sand vegetacion of Brazilian Amazonia". Biotropica 13, p. 199-210, 1981.

AVISE, J.C. Phylogeography. The history and formation of species. Cambridge: Harvard Univ. Press, 2000, 447 p.

AYRES, J. M. C. \& T. H. CLUTTON-BROCK. "River boundaries and species range size in Amazonian primates". Amer. Naturalist.140, 1992, p. 531-37.

BAKER, P.A., SELTZER, G.O., FRITZ, S.C., DUNBAR, R.B., GROVE, M.J., TAPIA, P.M., CROSS, S.L., ROWE, H.D. \& J.P. BRODA. "The history of South American tropical precipitation for the past 25,000 years". Science. 291: 2001, p. 640-43.

BARTLEIN, P.J. \& I. PRENTICE. “Orbital variations, climate and paleoecology”. Trends Ecol. Evol., 4, 1989, p. 195-99.

BATES, J.M. "Avian diversification in Amazonia: evidence for historical complexity and a vicariance model for a basic diversification pattern”. Bol. Mus. Para. Emílio Goeldi, Série Zoologia: no prelo; 2001. 
BEEHLER, B.M., PRATT, T.K. \& D.A. ZIMMERMAN. Birds of New Guinea. New Jersey, Princeton Univ. Press, 1986, 293 p.

BEHLING, H. "Der Amazonas-Regenwald im Wandel der Zeit". Naturwiss. Rundschau 54, 2001, p. 140-44.

BENNETT, K. D. "Evolution and ecology" in The pace of life. Cambridge Univ. Press, $1977,241 \mathrm{p}$.

BERGER, A., LOUTRE, M.F. \& V. DEHANT. "Pre-Quaternary Milankovitch frequencies". Nature. 342, 1989, p. 133.

BETTENCOURT, J.S., MUZZOLON, R. PAYOLlA, B.L., DALL'LGNA, L.G. \& O.G. PINHO DE. "Depósitos estaníferos secundários da região central de Rondônia". Principais Depósitos Minerais do Brasil 3. Brasília, Ministério das Minas e Energia, 1988, $670 \mathrm{p}$.

BIBUS, E. "Die klimamorphologische Bedeutung von stone-lines und Decksedimenten in mehrgliedrigen Bodenprofilen Brasiliens". Zeitschr. Geomorphol. N.F., Suppl. 48, 1983 , p. 79-98.

BIGARELLA, J. J. \& A. M. M. FERREIRA. "Amazonian geology and the Pleistocene and the Cenozoic environments and paleoclimates". In PRANCE, G. T. \& T. E. LOVEJOY (eds.): Amazonia. Oxford, Pergamon Press, 1985, p. 49-71, 442 p.

BRANDON-JONES, D. "The Asian Colobinae (Mammalia: Cercopithecidae) as indicators of Quaternary climatic change". Biol. J. Linnean Soc.. 59, 1996, p. 327-50.

BRANDON-JONES, D. "Pre-glacial Bornean primate impoverishment and WALLACE's line" in R. HALL \& J.D. HOLLOWAY (eds.). Biogeography and geological evolution of SE Asia. Backhuys Publ., Leiden, 1998, p. 393-404, 417 p.

BROWER, A.V.Z. "Parallel race formation and the evolution of mimicry in Heliconius butterflies: a phylogenetic hypothesis from mitochondrial DNA sequences". Evolution 50, 1996, p. 95-221.

BROWN JR., K.S. "Geographical patterns of evolution in Neotropical Lepidoptera: Systematics and derivation of known and new Heliconiini (Nymphalidae: Nymphalinae)". J. Entomol. B 44, 1976, p. 201-42.

BROWN JR., K.S. "Soils and vegetation". In: WHITMORE, T.C. \& G.T. PRANCE (eds.). Biogeography and Quaternary history in tropical America. Oxford: Clarendon Press, 1987a, p. 19-45, 214 p.

BROWN JR., K.S. "Biogeography and evolution of Neotropical butterflies”. In: WHITMORE, T.C. \& G.T. PRANCE (eds.): Biogeography and Quaternary history in tropical America. Oxford, Clarendon Press, 1987b, 66-104, 214 pp.

BROWN JR., K.S. "Conclusions, synthesis, and alternative hypotheses". In: WHITMORE, T.C. \& G.T. PRANCE (eds.): Biogeography and Quaternary history in tropical America. Oxford, Clarendon Press, 1987c, p. 175-96, 214 p.

BROWN JR., K.S. \& A.N. AB'SÁBER. "Ice-age forest refuges and evolution in the Neotropics: correlation of palaeoclimatological, geomorphological and pedological data with modern biological endemism". Paleoclimas (São Paulo). 5, 1979, p. 1-30.

BROWN, K.S., JR., SHEPPARD, P.M. \& J.R. TURNER. "Quaternary refugia in tropi- 
cal America: Evidence from race formation in Heliconius butterflies". Proc. R. Soc. London, B 187, 1974, p. 369-78.

BURNHAM, R. J. \& A. GRAHAM. "The history of Neotropical vegetation: New developments and status". Ann. Missouri Bot. Garden. 86, 1999, p. 546-89.

BUSH, M.B. “Amazonian speciation: a necessarily complex model”, Biogeogr. 21, 1994, p. 5-17.

CARNEIRO FILHO, A. \& J.A. ZINCK. "Mapping paleo-aeolian sand cover formations in the northern Amazon basin from TM images". ITC Journal, 3, 1994, p. 270-82.

CERQUEIRA, R. "South American landscapes and their mammals". In: MARES, M.A. \& H.H. GENÓWAYS (eds.): Mammalian Biology in South America. The Pymatuning Symposia in Ecology 6. University of Pittsburgh, 1982, p. 53-75, 539 p.

CLAPPERTON, C.M. "Nature of environmental changes in South America at the glacial maximum". Palaeogeogr. Palaeoclimat. Palaeoecol., 101, 1993a, p. 189-208.

CLAPPERTON, C.M. Quaternary geology and geomorphology of South America. Elsevier, Amsterdã, 1993b, 713 p.

COLINVAUX, P. A. "Pleistocene biogeography and diversity in tropical forests of South America". In: GOLDBLATT, P. (ed.): Biological relationships between Africa and South America. New Haven: Yale Univ. Press, 1993, p. 473-99, 630 p.

COLINVAUX, P. A. "Quaternary environmental history and forest diversity in the Neotropics”. In JACKSON, J. B. C., BUDD, A. F. \& A. G. COATES (eds.): Evolution and environment in tropical America. Univ. Chicago Press, 1996, p. 359-405, 425 p.

COLINVAUX, P. A. "A new vicariance model for Amazonian endemics". Global Ecol. Biogeogr. Lett. 7, 1998, p. 95-96.

COLINVAUX, P.A. \& DE OLIVEIRA, P. E. "Palaeoecology and climate of the Amazon basin during the last glacial cycle". J. Quaternary Sci., 15, 2000, p. 347-56.

COLINVAUX, P. \& DE OLIVEIRA, P. E. "Amazon plant diversity and climate through the Cenozoic". Palaeogeogr. Palaeoclimat. Palaeoecol., 166, 2001, p. 51-63.

COLINVAUX, P. A., DE OLIVEIRA, P. E., MORENO, J. E., MILlER, M. C. \& M. B. BUSH. "A long pollen record from lowland Amazonia: forest and cooling in glacial times". Science, 274, 1996, p. 85-88.

COLINVAUX, P. A., BUSH, M.B., STEINITZ-KANNAN, M. \& M. C. MILLER. "Glacial and postglacial pollen records from the Ecuadorian Andes and Amazon". Quaternary Res., 48, 1997, p. 69-78.

COLINVAUX, P. A., DE OliveirA, P. E. \& M. B. BUSH. "Amazonian and Neotropical plant communities on glacial time scales: The failure of the aridity and refuge hypotheses". Quaternary Sci. Rev., 19, 2000, p. 141-69.

COWLING, S. A., MASLIN, M. A. \& M. T. SYKES. "Paleovegetation simulations of lowland Amazonia and implications for Neotropical allopatry and speciation". Quaternary Res., 55, 2001, p. 140-49.

CROWE, T. M. \& A. A. CROWE. "Patterns of distribution, diversity and endemism in Afro-tropical birds". Londres, J. Zool., v. 198, 1982, p. 417-42. 
DARLINGTON, P. J. Zoogeography. The geographical distribution of animals. Nova York: Wiley \& Sons, Inc., 1957, 675 p.

DA SILVA, M. \& J. L. PATTON. "Amazonian phylogeography: mtDNA sequence variation in arboreal echimyid rodents (Caviomorpha)". Mol. Phyl. Evol., v. 2, 1993, p. 243-55.

EMMERICH, K. H. "Relief, Böden und Vegetation in Zentral- und Nordwest-Brasilien unter besonderer Berücksichtigung der känozoischen Landschaftsentwicklung". Frankfurter Geowissen-schaftliche Arbeiten, Serie D (Phys. Geographie), v. 8, 1988, p. 1-218.

FJELDSÅ, J., LAMBIN, E. \& B. MERTENS. "Correlation between endemism and local ecoclimatic stability documented by comparing Andean bird distributions and remotely sensed land surface data". Ecography, 22, p. 63-78, 1999.

FREITAS, H. A. DE, PESSENDA, L. C. R., ARAVENA, R., GOUVEIA, S. E. M., RIBEIRO, A. DE S. \& R. BOULET. "Late Quaternary vegetation dynamics in the southern Amazon basin inferred from Carbon isotopes in soil organic matter". Quaternary Res., 55, p. 39-46, 2001.

GARNER, H. F. The origin of landscapes. Oxford Univ. Press, 1974, 734 p.

GARNER, H. F. "Rainforests, deserts and evolution". Anais Acad. Brasil. Ciências, 47 (Suppl.), p. 127-33, 1975.

GASCON, C., LOUGHEED, S. C. \& J. P. BOGART. "Patterns of genetic population differentiation in four species of Amazonian frogs: A test of the Riverine Barrier hypothesis". Biotropica 30, p. 104-19, 1998.

GOLDBLATT, P. (ed.) Biological relationships between Africa and South America. New Haven: Yale Univ. Press, 1993, 630 pp.

GOTTSBERGER, G. \& W. MORAWETZ. "Floristic, structural and phytogeographical analysis of the savannas of Humaitá (Amazonas)”. Flora, 178, p. 41-71, 1986.

HABERLE, S. G. \& M. A. MASLIN. "Late Quaternary vegetation and climate change in the Amazon basin based on a 50,000 year pollen record from the Amazon fan. ODP site 932". Quaternary Res., 51, p. 27-38, 1999.

HAFFER, J. "Speciation in Amazonian forest birds". Science, 165, p. 131-37, 1969.

HAFFER, J. "Avian speciation in tropical America". Publ. Nuttall Ornith. Club, 14, 1974.

HAFFER, J. "General aspects of the refuge theory". In: PRANCE, G. T. (ed.): Biological diversification in the tropics. Nova York: Columbia Univ. Press, 1982, p. 6-24, 714 p.

HAFFER, J. "Quaternary history of tropical America". In: WHITMORE, T.C. \& G.T. PRANCE (eds.): Biogeography and Quaternary history in tropical America. Oxford: Clarendon Press, 1987, p. 1-18, 214 p.

HAFFER, J. "On the 'river effect' in some forest birds of southern Amazonia". Boi. Mus. Para. Emilio Goeldi, Série Zoologia 8, p. 217-45, 1992.

HAFFER, J. "Time's cycle and time's arrow in the history of Amazonia". Biogeographica 69, p. 15-45, 1993. 
HAFFER, J. "Contact zones between birds of southern Amazonia". Ornith. Monogr., 48, p. 281-305, 1997a.

HAFFER, J. "Alternative models of vertebrate speciation in Amazonia: an overview". Biodiv. Conserv., 6, p. 451-76, 1997b.

HAFFER, J. "Kontaktzonen bei Vögeln der Tropen und ihre biogeographische Bedeutung”. Ornithol. Anzeiger, 39, p. 43-62, 2000.

HARRINGTON, H. J. "Paleogeographic development of South America”. Bull. Amer. Assoc. Petrol. Geol., 46, p. 1773-1814, 1962.

HEINE, K. "The Mera site revisited: Ice-Age Amazon in the light of new evidence". Quaternary Int. 21, p. 113-19, 1994.

HERBERT, T. D. \& A. G. FISCHER. "Milankovitch climatic origin of mid-Cretaceous black shale rhythms in central Italy". Nature 321, p. 739-43, 1986.

HEWITT, G. "The genetic legacy of the Quaternary ice ages". Nature 405, p. 907-13, 2000.

HOOGHIEMSTRA, H. \& T. VAN DER HAMMEN. "Neogene and Quaternary development of the Neotropical rain forest: the forest refugia hypothesis and a literature overview". Earth Science Reviews 44, p. 147-83, 1988.

HOSTETLER, S. W. \& A. C. MIX. "Reassessment of ice-age cooling of the tropical ocean and atmosphere". Nature 399, p. 673-76, 1999.

HUBER, J.H. "Comparison of Old World and New World tropical cyprinodonts". Paris: Museum National d'Histoire Naturelle, Laboratoire d'Histoire Naturelle, Laboratoire d'Ichthyologie Générale, 109 p., 1998.

IRIONDO, M. \& E.M. LATRUBESSE. "A probable scenario for a dry climate in central Amazonia during the late Quaternary". Quaternary Int. 21, p. 121-28, 1994.

JONES, N. "Never say die". New Scientist 169 (2275), p. 36-39, 2001.

JOSEPH, L., MORITZ, C. \& A. HUGALL. "Molecular support for vicariance as a source of diversity in rainforest". Proc. R. Soc. London, B 260, p. 177-82, 1995.

JOURNAUX, A. "Recherches géomorphologiques en Amazonie". Paris, CNRS 28, p. $1-68,1975$.

KEAST, A. "Bird speciation on the Australian continent". Buli. Mus. Comp. Zool. 123, p. 305-495, 1961.

KLAMMER, G. "The relief of the extra-Andean Amazon basin: 47-83". In: SIOLI, H (ed.): The Amazon. Limnology and landscape ecology of a mighty tropical river and its basin. Dordrecht: Junk Publ., 763 p., 1984.

KRONBERG, B.I., BENCHIMOL, R.E. \& M.I. BIRD “Geochemistry of Acre Subbasin sediments: window on Ice-Age Amazonia”. Interciência 16, p. 138-41, 1991.

LATRUBESSE, E. M. \& A. RANCY. "The late Quaternary of the upper Juruá River, southwestern Amazonia, Brazil: geology and vertebrate palaeontology". Quaternary of South America and Antarctic Peninsula 11, p. 27-46, 1998.

LEDRU, M.-P., BERTAUX, J., SIFEDDINE, A. \& K. SUGUIO. "Absence of Last Glacial Maximum records in lowland tropical forests". Quaternary Res. 49, p. 233-37, 1998. 
LÉVÊQUE, C. Biodiversity dynamics and conservation. The freshwater fish of tropical Africa. Cambridge Univ. Press, 1997, 438 p.

MARROIG, G. \& R. CERQUEIRA. "Plio-Pleistocene South American history and the Amazon Lagoon hypothesis: a piece in the puzzle of Amazonian diversification". J. Comp. Biol. 2, p. 103-19, 1997.

MARSHALL, L.G. "A model for paleobiogeography of South American cricetine rodents". Paleobiology 5, p. 126-32, 1979.

MASLIN, M. A. \& S. J. BURNS. "Reconstruction of the Amazon Basin effective moisture availability over the past 14,000 years". Science 290, p. 2.285-87, 2000.

MAYLE, F.E., BURBRIDGE, P. \& T.J. KILLEEN. "Millennial scale dynamics of Southern Amazonian rainforests". Science 290, p. 2291-94, 2000.

MAYR, E. Systematics and the origin of species from the viewpoint of a zoologist. Nova York: Columbia Univ. Press, 1942, 334 p.

MAYR, E. Animal species and evolution. Cambridge: Harvard Univ. Press, 1963, 797 p.

MAYR, E. \& R.J. O'HARA. "The biogeographic evidence supporting the Pleistocene forest refuge hypothesis". Evolution 40, p. 55-67, 1986.

MOREAU, R.E. The bird faunas of Africa and its islands. Londres, Academic Press, 1966, 424 p.

MORLEY, R.J. Origin and evolution of tropical rain forests. New York: Wiley \& Sons, 2000, 325 p.

MÜLLER, J., IRION, G., NUNES DE MELLO, J. \& W. JUNK. "Hydrological changes of the Amazon during the last glacial-interglacial cycle in central Amazonia". Naturwiss. 82, p. 232-35, 1995.

MÜLLER, P. The dispersal centres of terrestrial Vertebrates in the Neotropical realm. Junk Publ., The Hague, 1973, 244 p.

NORES, M. "An alternative hypothesis for the origin of Amazonian bird diversity". J. Biogeogr. 26, p. 475-85, 1999.

OLSEN, P.E.A. "40-million-year lake record of early Mesozoic orbital climatic forcing”. Science 234, p. 842-48, 1986.

PATTON, J.L., DA SILVA, M.N. LARA, M.C. \& M.A. MUSTRANGI. "Diversity, differentiation and the historical biogeography of nonvolant small mammals of the Neotropical forests", p. 455-65. In: LAURANCE, W.F. \& R.O. BIERREGAARD JR (eds.): Tropical forest remnants: Ecology, management and conservation of fragmented communities. Chicago: Univ. of Chicago Press, 1997, 587 pp.

PATTON, J.L. \& M.N.F. DA SILVA. "Rivers, refuges, and ridges. The geography of speciation of Amazonian mammals". In: HOWARD, D.J. \&;S.H. BERLOCHER (eds.) Endless Forms: Species and Speciation. Nova York: Oxford Univ. Press, 1998, p. 202$13,470 \mathrm{p}$.

PATTON, J.L., DA SILVA, M.N., \& J.R. MALCOLM. "Mammals of the Rio Juruá and the evolutionary and ecological diversification of Amazonia". Bull. Amer. Mus. Nat. Hist. 244, p. 1-306, 2000. 
PETRI, S. \& V.J. FÚLFARO. Geologia do Brasil. Universidade de São Paulo, 1983, 631 p.

PRANCE, G.T. "Phytogeographic support for the theory of Pleistocene forest refuges in the Amazon basin, based on evidence from distribution patterns in Caryocaraceae, Chrysobalanaceae, Dichapetalaceae and Lecythidaceae". Acta Amazônica 3, p. 5-28, 1973.

PRANCE, G.T. "Discussion”. In: NELSON, G. \& D.E. ROSEN (eds.): Vicariance Biogeography: A Critique. Nova York: Columbia Univ. Press, 1981, p. 395-405, 593 p.

PRANCE, G.T. "A review of the phytogeographic evidences for Pleistocene climate changes in the Neotropics". Ann. Missouri Bot. Garden 69, p. 594-624, 1982a.

PRANCE, G.T. (ed.) Biological diversification in the tropics. Nova York, Columbia Univ. Press, 1982b, $714 \mathrm{p}$.

PRANCE, G.T. "Biogeography of Neotropical plants”. In: WHITMORE, T.C. \& G.T. PRANCE (eds.): Biogeography and Quaternary history in tropical America. Oxford Monogr. Biogeogr. 3: p. 46-65, 214 p., 1987.

PRANCE, G.T. "Islands in Amazonia”. Phil. Trans. R. Soc. London B 351, p. 823-33, 1996.

PRATT, T.K. "Biogeography of birds in New Guinea". In: GRESSIT, J.L (ed.): Biogeography and Ecology of New Guinea. Junk Publ., The Hague, 1982, p. 815-36, $941 \mathrm{p}$.

RANCY, A. "Pleistocene mammals and paleoecology of the western Amazon". Tese de Ph.D, Univ. of Florida, EUA, 164 p., 1991.

RANCY, A. "A paleofauna da Amazônia indica áreas de pastagem com pouca cobertura vegetal”. São Paulo, Ciência Hoje, 16, p. 48-51, 1993.

RÄSÄNEN, M.E., LINNA, A.M., SANTOS, J.C.R. \& F.R. NEGRI. "Late Miocene tidal deposits in the Amazonian foreland basin". Science 269, p. 386-96, 1995.

RON, S.R. "Biogeographic area relationships of lowland Neotropical rainforest based on raw distributions of vertebrate groups". Biol. J. Linn. Soc. 71, p. 379-402, 2000.

ROOSMALEN, M.G.M. VAN, ROOSMALEN, T. VAN, MITTERMEIER, R.A. \& A.B. RYLANDS. "Two new species of marmoset, genus Callithrix Erxleben, 1777 (Callitrichidae, Primates), from the Tapajós/Madeira interfluvium, south central Amazonia, Brazil”. Neotropical Primates, 8, p. 2-18, 2000.

ROY, M.S., DA SILVA, J.M.C., ARCTANDER, P., GARCIA-MORENO, J. \& J. FJELDSA. "The speciation of South American and African birds in montane regions". In: MINDELL, D.P. (ed.) Avian molecular evolution and systematics. San Diego, Academic Press, 1997, p. 325-43, 382 p.

SALATI, E. "The climatology and hydrology of Amazonia". In: PRANCE, G. T. \& T.E. LOVEJOY (eds.) Amazonia. Oxford: Pergamon Press, p. 18-48, 442 p., 1985.

SANTOS, J.O.S., NELSON, B.W. \& C.A. GIOVANNINI. "Corpos de areia sob leitos abandonados de grandes rios”. São Paulo, Ciência Hoje 16, p. 22-25, 1993.

SCHNEIDER, C.J., CUNNINGHAM, M. \& C. MORITZ. "Comparative phylogeography and the history of endemic vertebrates in the Wet Tropics rainforests of Australia". Mol. Evol. 7, p. 487-98, 1998. 
SCHUBERT, C. "Climatic change during the last glacial maximum in northern South America and the Caribbean: a review". Interciência 13, p. 128-37, 1988.

SECCO, R. DE S. \& A.L. MESQUITA. "Notas sobre a vegetação de Canga da Serra Norte - 1. Boi. Mus. Para. Emilio Goeldi, Sér. Botânica 59, p. 1-13, 1983.

SIFEDDINE, A., FROHLICH, F., FOURNIER, M., MARTIN, L., SERVANT, M., SOUBIES, F., TURQ, B., SUGUIO, K. \& C. VOLKMER-RIBEIRO. "La sédimentation lacustre indicateur de changements des paléoenvironnements au cours des 30,000 dernières années (Carajás, Amazonie, Brésil)". C.R. Acad. Sci. Paris 318(2), p. 1.645$52,1994$.

SIMPSON, B.B. \& J. HAFFER. "Speciation patterns in the Amazonian forest biota". Ann. Rev. Ecol. Syst. 9, p. 497-518, 1978.

STRESEMANN, E. "Über die europäischen Baumläufer". Verh. Ornith. Ges. Bayern 14, p. 39-74, 1919.

STRESEMANN, E. \& H. GROTE. "Verbreitung und Gliederung afrikanischer Formenkreise". Verh. VIth Int. Ornith. Kongr. (Kopenhagen, 1926), p. 358-74, 1929.

THOMAS, M.F. "Late Quaternary environmental changes and the alluvial record in humid tropical environments". Quaternary Int. 72, 2000, p. 23-36.

THOMPSON, L.G., MOSLEY-THOMPSON, E., DAVIS, M.E. LIN, P.-N., HENDERSON, K.A., COLEDAI, J., BOLZAN, J.F. \& K.-B. LIU. "Late glacial stage and Holocene tropical ice core records from Huascarán, Peru”. Science, 269, p. 46-50, 1995.

TREGENZA, T. \& R.K.. BUTLIN. "Speciation without isolation". Nature, 400, p. 311-12, 1999.

TRICART, J. "Existence de périodes sèches au Quaternaire en Amazonie et dans les regions voisines". Rev. Géomorph. Dynam. 4, p. 145-58, 1974.

TRICART, J. "Evidence of upper Pleistocene dry climates in northern South America". In: DOUGLAS, I. \& T. SPENCER (eds.) Environmental change and tropical geomorphology. School of Geography, Univ. of Manchester, 1985, p. 196-220, 382 p.

VAN DER HAMMEN, T. \& M.L. ABSY. "Amazonia during the last glacial”. Palaeogeogr. Palaeoclimat. Palaeoecol. 109, p. 247-61, 1994.

VAN DER HAMMEN, T. \& H. HOOGHIEMSTRA. "Neogene and Quaternary history of vegetation, climate, and plant diversity in Amazonia". Quaternary Sci. Rev. 19, p. 725-42, 2000.

VANZOLINI, P.E. "Paleoclimates, relief, and species multiplication in equatorial forests: 255-258". In: MEGGERS, B.J., AYENSU, E.S. \& W.D. DUCKWORTH (eds.) Tropical forest ecosystems in Africa and South America: a comparative review. Washington, D.C.: Smithsonian Institution Press, 1973, 350 p.

VANZOLINI, P.E. "Paleoclimas e especiação em animais da América do Sul tropical". São Paulo, Estudos Avançados, 6 (15), p. 41-65, 1992.

VANZOLINI, P.E. \& E.E. WILLIAMS. "South American anoles: Geographic differentiation and evolution of the Anolis chrysolepis species group (Sauria, Iguanidae)". São Paulo, Arquivos de Zoologia, 19, p. 1-298, 1970. 
VANZOLINI, P.E. \& E.E. WILLIAMS. "The vanishing refuge: a mechanism for ecogeographical speciation”. São Paulo, Papéis AvulsosZool., 34 (23), p. 251-55, 1981.

VEIGA, A.T.C. "Paleoenvironmental and archeological significance of alluvial placers of the Brazilian Amazon". Proc. Symp. on Global Changes in South America during the Quaternary. São Paulo, Boletín IG-USP, publicação especial, 8, p. 213-22, 1991.

VEIGA, A.T.C., DARDENNE, M.A. \& E.P. SALOMÃO. "Geologia dos aluviões auríferos e estaníferos da Amazônia”. Belém, Anais do 35 Cong. Geol., 1, p. 164-77, 1988.

VRBA, E.S. "Mammals as a key to evolutionary theory”. J. Mammal, 73, p. 1-28, 1992.

VRBA, E.S. "Mammal evolution in the African Neogene and a new look at the Great American Interchange". In: GOLDBLATT, P. (ed.) Biological relationships between Africa and South America. New Haven: Yale Univ. Press, 1993, p. 393-432, 630 p.

VRBA, E.S. "On the connections between paleoclimate and evolution". In: VRBA, E.S., DENTON, G.H., PARTRIDGE, T.C. \& L.H. BURCKLE (eds.): Paleoclimate and evolution, with emphasis on human origins. Yale Univ. Press, New Haven, 1995, p. $24-45,547 \mathrm{p}$.

VRBA, E.S., DENTON, G.H., PATRIDGE, T.C. \& L.H. BURCKLE (eds.) Paleoclimate and evolution, with emphasis on human origins. New Haven: Yale Univ. Press, 1995, $547 \mathrm{p}$.

VUILLEUMIER, B.S. "Pleistocene changes in the fauna and flora of South America". Science, 173, p. 771-80, 1971.

WALLACE, A.R. "On the monkeys of the Amazon". Proc. Zool. Soc. London, 20, p. $107-10,1852$.

WEBB, S.D. "Ecogeography and the Great American Interchange'. Paleobiology 17, p. 266-80, 1991.

WEBB, S.D. \& A. RANCY. "Late Cenozoic evolution of the Neotropical mammal fauna". In JACKSON, J.B.C., BUDD, A.F. \& A.G. COATES (eds.): Evolution and environment in tropical America. Chicago: Univ. Chicago Press, 1996, p. 335-58, 425 p.

WILLIAMS, S.E. \& R.G. PEARSON. "Historical rainforest contractions, localized extinctions and patterns of vertebrate endemism in the rainforests of Australia's wet tropics". Proc. R. Soc. London, B 264, p. 709-17, 1997.

WILLIS, K.J. \& RJ. WHITTAKER. "The refugial debate”. Science, 287, p. 1406-07, 2000 .

ZACHOS, J.C., FLOWER, B.P. \& H. PAUL. "Orbitally paced climate oscillations across the Oligocene/Miocene boundary”. Nature, 388, p. 567-70, 1997.

ZACHOS, J., PAGANI, M. SLOAN, L. THOMAS, E. \& K. BILLUPS. "Trends, rhythms, and aberrations in global climate 65 Ma to present". Science, 292, p. 686$93,2001$. 


\section{Adenda}

Neste artigo, baseamos nossas análises acerca da história climático-vegetacional da Amazônia em dados de campo e interpretações de especialistas em vários ramos das ciências, indicando o efeito de fases climáticas secas em partes da Amazônia durante períodos geológicos diferentes. Esses cientistas são: os palinologistas T. van der Hammen, H. Hooghiemstra e M. Absy; os geomorfologistas A. N. Ab’Sáber, E. Bibus, J. J. Bigarella, A. Journaux, M. Iriondo, J. S. Bettencourt, B. I. Kronberg, E. M. Latrubesse, M.-P Ledru, J. Bertaux, J. O. S. Santos, K. Suguio, J. Tricart e A. T. C. Veiga; e os paleontólogos A. Rancy e S.D. Webb.

Em seus comentários críticos sobre a teoria dos Refúgios, Colinvaux et al. (2001) sustentam que as interpretações de todos os cientistas mencionados acima são espúrias, porque supostamente distorceram e, em geral, interpretaram erroneamente seus dados de campo em favor da idéia preconcebida de aridez no período glacial. Com certeza essas alegações um tanto simplistas levarão a intensas discussões entre os cientistas da Terra nos anos futuros.

Segundo Colinvaux et al. (1.c.), climas tropicais úmidos com condições atmosféricas úmidas prevaleceram na Amazônia, desde pelo menos o Mioceno, com nenhuma fase seca interrompendo a história climática continuamente úmida dessa região (exceto para pequenas flutuações vegetacionais em partes periféricas da Amazônia). Esses autores não comentaram especificamente os dados de campo de Bibus (1983), Veiga (1991) e Veiga et al. (1988), que apóiam nossas interpretações. Bibus (1.c.) descreveu perfis complexos de solo e a ocorrência muito difundida de fragmentos grosseiros na Amazônia SubCentral e chamou a atenção para a existência de espessas camadas de sedimentos grosseiros nos terraços do Pleistoceno encontrados na Amazônia Inferior (e cuja origem requer uma explicação). Ele estudou os cortes nos terrenos ao longo da construção da Transamazônica, ao sul de Santarém e, entre outros fenômenos, descreveu uma "linha de seixos consistindo de fragmentos angulares de quartzo. A forma e a textura desses pedaços de quartzo indicam que eles não se originaram através de precipitação secundária de sílica, mas sem dúvida são cascalhos residuais derivados de veios de quartzo no interior do afloramento de granito. Portanto, essa linha de seixos pode ser tomada, inequivocamente, como prova de uma fase erosional anterior" nessa região (Bibus, l.c., p. 83). Mencionamos esta observação aqui como uma lembrança de que, além das "pseudolinhas de seixos" consistindo de concreções (tratadas em extensão por Colinvaux et al., l.c.), verdadeiras linhas de seixos também existem na Amazônia. Veiga et. al (1.c.) descreveram sedimentos grosseiros e pobremente sortidos subjacentes à vegetação de floresta pluvial ao norte de Manaus e nas bacias dos Rios Tapajós e Xingu, e analisaram as implicações paleoecológicas desses depósitos. É claro que estudos de campo adicionais nessas regiões são altamente desejáveis.

As asserções de Colinvaux et al. (2001) ilustram duas das noções erradas acerca da teoria dos Refúgios que mencionamos em nosso texto: 1 a proposta do modelo ao longo desses 30 anos baseou-se, supostamente, apenas nos padrões bióticos atuais, quando na verdade também os resultados previamente publicados de estudos geomorfológicos e palinológicos têm sido usados; 2 mudanças vegetacionais que ocorreram na Amazônia supostamente alternadas entre floresta pluvial e savana de gramíneas, quando de fato foram consideradas mudanças muito mais complexas de floresta úmida para floresta seca, floresta de lianas, floresta de bambus e outros tipos de vegetação de climas sazonalmente quentes. 
Concluindo esta breve adenda gostaríamos de chamar a atenção de que, ao contrário do que Colinvaux et al. (1.c) afirmam, nós não tentamos desacreditar todas as alternativas de modelos de especiação propostas para a Amazônia mas, ao contrário, declaramos que alguns aspectos da maioria deles podem ser aplicáveis a certos períodos na evolução da biota. Ressaltamos, todavia, a significância (poder explanatório) muito diferente dos vários modelos alternativos dependendo de se referirem a longo período de tempo e efeitos recorrentes da formação de barreira (altamente significante) ou a curto período geológico e excepcionais eventos históricos (baixa significância).

COLINVAUX, P.A., IRION, G., RÄSÄNEN, M.E., BUSH, M.B. \& J.A.S. NUNES DE MELLO. "A paradigm to be discarded: geological and paleoecological data falsify the HAFFER \& PRANCE refuge hypothesis of Amazonian speciation". Amazoniana, $16(3 / 4)$, p. 609-46, 2001.

RESUMO - AS FLUTUAÇÕES climático-vegetacionais causadas pelos ciclos astronômicos de Milankovitch provocaram mudanças globais na distribuição de florestas tropicais e demais vegetações não-florestais antes e durante o Cenozóico (Terciário-Quaternário). Os biomas continentais de florestas e vegetações não-florestais mudaram continuamente sua distribuição durante o seu passado geológico, fragmentando-se em blocos isolados, expandindo-se e juntando-se novamente sob condições climáticas alternadas entre secas e úmidas. Entretanto, durante as diversas fases climáticas, comunidades de plantas e animais fragmentaram-se e as espécies mudaram suas distribuições de maneira individual. Existem, para o Quaternário, dados de campo indicando mudanças na vegetação da Amazônia.

A teoria dos Refúgios postula a persistência de grandes manchas de florestas tropicais úmidas durante os períodos secos do Terciário e do Quaternário, especialmente aquelas localizadas próximo de superfícies rebaixadas, sobretudo nas porções periféricas da Amazônia. Essas áreas são, provavelmente, a origem de muitas espécies e subespécies de plantas e animais existentes hoje em dia. Os "refúgios" úmidos podem ter sido separados por vários tipos de savana e florestas secas, como também por outros tipos de vegetação intermediária de climas sazonalmente secos. A quantidade e o tamanho dos refúgios durante os diferentes períodos de seca continuam desconhecidos. Indícios biogeográficos da existência de refúgios florestais anteriores incluem áreas de endemismo e zonas de contato entre espécies e subespécies de pássaros e outros animais da floresta amazônica nitidamente definidos. Essas áreas representam zonas de distinta descontinuidade biogeográfica num ambiente florestal contínuo.

Modelos alternativos para a formação de barreiras na Amazônia que conduzem à especiação alopátrica incluem as seguintes hipóteses: do Rio, dos Refúgios do Rio, da Densidade do Dossel, da Perturbação da Vicariânia, do Museu e várias hipóteses paleogeográficas, das quais alguns aspectos poderiam ser aplicáveis a certos períodos na evolução da biota.

Jürgen Haffer estudou geologia, paleontologia e biologia na Universidade de Göttingen, onde obteve $\mathrm{PhD}$ em 1957.

Ghillan T. Prance é pesquisador do National Tropical Botanic Garden, Havaí, EUA.

Os autores dedicam o artigo ao professor Harald Sioli, por ocasião de seu $90^{\circ}$ aniversário.

Os autores são gratos a Ernst Mayr (Cambridge, Massachusetts) pelas considerações a respeito da matéria de que trata este artigo, a John Bates (Chicago), Erhard Bibus (Tübingen) e a diversos críticos anônimos por chamarem a atenção para publicações relevantes.

Artigo publicado originalmente em Amazoniana, XVI, (3/4): 579-607. Kiel, dez. 2001. Tradução de Antônio Lamberti. O original em inglês encontra-se à disposição do leitor no IEA-USP para eventual consulta. 